\title{
9. El proceso de escritura académica de estudiantes universitarios en un aula remota de escritura
}

\author{
Rita FlóRez ROMERO \\ AndRÉS HeNAo FlóReZ \\ Lina Emilena Niño Aguilera
}

E

I presente capítulo pretende contribuir a la discusión sobre los programas para mejorar las competencias en escritura a nivel universitario, a través de una experiencia de la Universidad Nacional de Colombia con estudiantes de primeros semestres en las diferentes sedes de la institución (Arauca, Bogotá y Caribe), durante el curso Comunicación oral y escrita del primer semestre del 2014. El objetivo es identificar las condiciones que hicieron posible el funcionamiento de un Aula Remota de escritura en dicho curso. ¿Cómo son los factores institucionales, tecnológicos, didácticos que influyeron en el proceso de escritura llevado a cabo dentro del curso? En la experiencia que analizamos participaron 40 estudiantes de la sede Bogotá, todos estudiantes de diferentes programas de pregrado. La metodología de esta experiencia académica se relaciona con la instrucción de los procesos escriturales de manera virtual y tutorial a través de videoconferencias y manejo de la plataforma Blackboard, enfocada a la producción de textos académicos de índole argumentativo. Los resultados y conclusiones de esta investigación se orientan a una aproximación cualitativa sobre las implicaciones que tiene en la escritura académica la configuración de aulas remotas de escritura en el proceso de escritura académica de estudiantes universitarios.

Rita Flórez-Romero. Fonoaudiología por la Universidad Nacional de Colombia y magíster en Lingüística con énfasis en sociolingüística por la misma universidad. Docente asociada de la Universidad Nacional de Colombia. e-mail: rflorezr@unal.edu.co

Andrés Henao Flórez. Magíster en Comunicación y Educación por la Universidad Autónoma de Barcelona, Candidato Mg en Educación Universidad de los Andes y Docente de Cátedra de la Universidad de La Sabana, email: andres.henao@unisabana.edu.co

Lina Emilena Niño Aguilera. Fonoaudióloga y magíster en Salud y Seguridad en el Trabajo por la Universidad Nacional de Colombia. Coinvestigadora en el Grupo de Cognición y Lenguaje en la Infancia. e-mail: Ieninoa@unal.edu.co 


\section{Introducción}

Esta investigación se inscribe dentro del campo de estudio de la alfabetización académica, concepto que se viene desarrollando desde hace más de diez años y abarca el "conjunto de estrategias necesarias para participar en una comunidad discursiva, en este caso, a las prácticas de lenguaje y pensamiento propias del ámbito académico superior" (Carlino, 2013).

La universidad corresponde a uno de los lugares en los que se genera conocimiento por excelencia y lleva a cabo un rol importante dentro de la sociedad de la información y el conocimiento; por ello, es preciso contemplar el desarrollo de nuevas habilidades que permitan aprovechar, por ejemplo, las utilidades que oferta el uso de las tecnologías de la información y de la comunicación (TIC), para decantar, compartir y comunicar el conocimiento.

En este contexto, germinan nuevas maneras de leer, escribir, aprender y comunicarse; por ello, la educación superior no puede solo centrarse en fomentar competencias relacionadas con el ámbito profesional, sino también en la posibilidad de desarrollar habilidades que permitan al estudiante universitario ser una persona que pueda ser capaz de integrarse exitosamente a la creciente sociedad de la información (Henao, 2016).

De igual forma, la preocupación por la escritura y la lectura de los estudiantes universitarios ha tenido una larga tradición investigativa (Carlino, 2003; Castelló, 2007). La discusión ha girado en torno a la brecha entre las competencias para leer y escribir textos en el nivel secundario y las exigencias académicas del nivel universitario. Se han advertido, por un lado, las dificultades de muchos estudiantes para comprender y producir textos académicos, y por otro, que esa dificultad está asociada al hecho de que el dominio de cada disciplina implica la enseñanza-aprendizaje de ciertos modos de leer y escribir específicos (Bazerman et al., 2010). De ahí se desprende la necesidad de que la escritura académica en la universidad sea una especie de cultura que impregna los currículos y las prácticas de la institución (Flórez y Gutiérrez, 2012).

También los avances en las TIC y el constante desarrollo de herramientas multimedia e interactivas en línea y plataformas de e-learning en la actualidad se han abordado como alternativas para trabajar los procesos de lectura y escritura. Su uso se ha extendido en el contexto universitario en diferentes áreas disciplinares, incluso en los cursos relacionados con aspectos de lenguaje y comunicación oral y escrita, aprovechándolas como una forma que facilita diversos aprendizajes, orientando la utilidad de la tecnología y sus aplicaciones para lograr un fin educativo (González y Muñetón, 2002; Álvarez, 2012). 
Respecto de considerar los ambientes de enseñanza-aprendizaje con el uso de las TIC, permite observarlos como sistemas que ayudan a estudiantes y docentes a tomar el control y la gestión de su propio aprendizaje, incluso las actividades de los estudiantes para fijar sus propias metas de aprendizaje, la gestión de los contenidos y procesos y la interacción virtual de comunicarse con otros durante el transcurso y así lograr objetivos individuales y colectivos (Atwell, 2007).

Lo anterior permite considerar el ambiente académico como un concepto de conjunción entre la tecnología y la pedagogía, donde estos dos elementos se retroalimentan a través de diferentes herramientas, fuentes de información, conexiones y actividades que cada persona utiliza para aprender (Adell y Castañeda, 2010).

\section{Aula remota}

Observando la necesidad de que los estudiantes que ingresan a la Universidad Nacional de Colombia refuercen sus competencias en lectura y escritura para el aprendizaje de las diferentes disciplinas, desde 2011, el Departamento de Comunicación Humana de la Facultad de Medicina realizó el curso con componente virtual Comunicación Oral y Escrita (2011 II-2014 I).

El curso se impartió en las aulas virtuales de UN virtual sede Bogotá, por videoconferencia y compartiendo escritorio, es decir, los estudiantes podían ver en tiempo real la presentación de la docente y esta podía ver los talleres y actividades que realizaban los estudiantes de diferentes sedes de presencia nacional (Arauca y Caribe). Además, en Bogotá, por cada treinta estudiantes, se contaba con la colaboración de un tutor encargado de monitorear y apoyar el trabajo de los estudiantes a su cargo. En las sedes de presencia nacional también se disponía de un tutor contratado por cada sede y el docente a cargo de la asignatura hacía presencia una vez al mes en la región para encontrarse personalmente con los estudiantes y aclarar dudas sobre sus procesos de escritura. Este modelo mixto adapta las características de un aula remota, es decir, conserva ciertos aspectos del aula presencial pero se vale de plataformas tecnológicas, como el software de aprendizaje electrónico Blackboard y canales de comunicación como el correo electrónico, el chat y demás para profundizar en el acompañamiento a los estudiantes. (Escamilla, 2007)

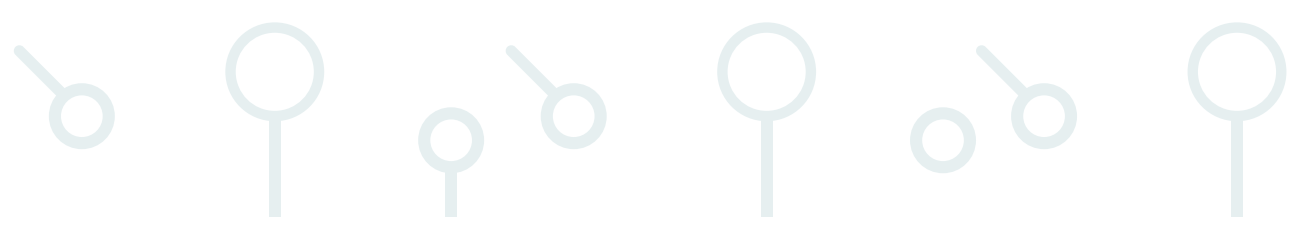




\section{Escritura como proceso}

Desde su planeación, el curso se basó en la perspectiva de la escritura como proceso, que otorga al acto de elaborar un texto un valor comunicativo y epistémico. Se escribe pensando en llegar a una audiencia con un determinado mensaje y que los conceptos y las ideas de cada disciplina, lo que hemos llamado saber universitario, se construye mientras escribimos. Entender la escritura como una herramienta a la vez cognitiva y persuasiva exige el reto de centrarse en su proceso, es decir, en las operaciones mentales que implica la producción de un texto y no solo en su resultado (Barnett, 1989). En últimas, se escribe para organizar, comunicar y construir el conocimiento. Por tanto, nuestra pregunta se centra en comprender las condiciones o factores que influyeron en los estudiantes durante la ejecución del conjunto de actividades, previas y subsiguientes a la elaboración de un texto, dentro de un aula remota de escritura.

Teniendo en cuenta lo anterior, el asunto que aborda este estudio es comprender las condiciones que hicieron posible el funcionamiento del aula remota de escritura en el curso Comunicación Oral y Escrita en el proceso escritural de sus estudiantes y en los textos finalizados durante aquel, que son en últimas el corpus analizado.

\section{Categorías de análisis}

Para el análisis de la información, hemos tomado el modelo 3P (Dunkin y Bidle, 1974) que describe el proceso de enseñanza-aprendizaje y el funcionamiento de un aula en tres fases: 1) presagio, 2) proceso y 3) producto. Los factores de presagio implican aspectos contextuales (del alumno y de la enseñanza) previos a la acción educativa en un aula remota. En esta categoría, tenemos en cuenta los factores institucionales, el apoyo de las sedes, la implicación de otros maestros e instancias de la universidad en el curso, así como la dotación tecnológica con la que contó este, las características del software y las plataformas tecnológicas usadas. Como segundo criterio de análisis, encontramos el nivel del proceso o la didáctica de escritura del curso, el conjunto de actividades y ejercicios que realizaron docentes y estudiantes, ejercicios todos relacionados con la enseñanza-aprendizaje de las operaciones propias del proceso de escritura, planeación, transcripción y edición de un texto (Flórez y Cuervo, 2005).

Por último, tenemos la categoría de producto, en la que se valoraron competencias relacionadas con la escritura, como la capacidad de sintetizar, exponer o parafrasear, y la capacidad para construir argumentos sólidos que comuniquen de forma coherente a la audiencia del texto una idea propia del autor. Para ello, analizaremos la prueba inicial a la que se sometieron los estudiantes para identificar su nivel de entrada al curso en cuanto a habilidades 
básicas de comprensión y producción textual, y el ejercicio final del curso donde se le propone al estudiante la puesta en marcha simultánea de todas las operaciones relacionadas con la producción de un texto, presentes en la escritura académica experta.

\section{Antecedentes del curso}

Como otras universidades de América Latina, en los últimos veinte años, la Universidad Nacional de Colombia ha hecho un esfuerzo por desarrollar programas que permitan el desarrollo de habilidades escriturales y orales que influyan positivamente en el desempeño académico de los estudiantes de los diferentes programas académicos que se ofertan. En 1997, se puso en marcha el Programa de Optimización del Desempeño Académico, liderado por la División de Salud Estudiantil. En dicho programa, se abrieron espacios de consultoría y asesoría sobre habilidades académicas a estudiantes de la universidad que lo requerían. Alí mismo se abrieron espacios para practicantes de fonoaudiología, lo cual, posteriormente, hacia 2005, se convirtió oficialmente en el Centro de la Comunicación Humana, ubicado en la Facultad de Medicina. Por otro lado, alrededor de 2001-2009, se creó el proyecto DesarroIlo de estrategias de acompañamiento escritural Laboratorio UN escribe del Departamento de la Comunicación Humana. De igual manera, en 2006, la Vicedecanatura de Bienestar de la Facultad de Medicina creó el curso Programa de mejoramiento de las competencias comunicativas de los estudiantes de la Facultad de Medicina Escritores UN.

\section{Antecedentes de las aulas remotas de escritura}

Nuestro primer antecedente se encuentra en el término escritura asistida por computador que se refiere al conjunto de herramientas informáticas que soportan el desarrollo, la organización y la redacción de textos escritos por parte de los estudiantes (Waldrep, 1990). Esta expresión se acuñó a principios de la década de 1980 para englobar las primeras herramientas de asistencia en la escritura y corrección de estilo (Oakman, 1984). Los primeros asistentes se basaban en reglas gramaticales codificadas en listas, con las cuales el usuario podía obtener sugerencias acerca de palabras, pronombres, frases de transición e identificación de tiempos de conjugación, entre otras funcionalidades (Waldrep, 1990). A finales de la década de 1980, se incluyeron nuevas funcionalidades, como el soporte en línea por parte de tutores conectados con el autor, para la corrección de estilo y la colaboración en grupo en el proceso de escritura (Waldrep, 1990).

El soporte en línea permitió a las herramientas de apoyo a la escritura sugerir automáticamente correcciones sin intervención del usuario. Esta línea se ha venido desarrollando 
aceleradamente en los últimos años (Bolshakov y Gelbukh, 2004). Sin embargo, su impacto en la calidad de los textos escritos es todavía materia de debate (Kelly, 2002). Por su parte, la colaboración grupal, que es muy cercana a la experiencia del curso Comunicación Oral y Escrita, soporta la interacción entre los miembros de una red de escritura, con un sistema de versionamiento, o de compartir pantallas y escritorios, que permite el seguimiento del proceso de construcción del documento y la realización de las correcciones necesarias (Oakman, 1984

El sistema descrito permite insertar anotaciones sobre textos digitales y almacenar los errores más frecuentes en la construcción de estos. En este sentido, Sharples (1994) propone una dinámica cíclica de reflexión-planeamiento-compromiso-relectura, modelada a través de una vista de notas, en la cual el usuario puede escribir sus ideas y enlazarlas en una estructura de red, una vista estructural en la cual el escritor crea y manipula un resumen del texto y una vista lineal que le permite al escritor escribir sin interferencias. El asistente permite intercambiar entrevistas y enlazar información de las tres fuentes rápidamente que tienen en cuenta el proceso de planeación previo a la construcción de un texto escrito (Flórez y Cuervo, 2006).

\section{Objetivos del trabajo investigativo}

Los siguientes son los objetivos generales del trabajo investigativo:

- Comprender la influencia de diferentes condiciones que convergen para el adecuado funcionamiento de un aula remota de escritura en un curso universitario.

- Identificar las condiciones generales necesarias para el funcionamiento de un aula remota de escritura en una universidad.

- Comprender cómo las universidades adoptan una cultura de escritura en torno al reto de las alfabetizaciones académicas.

- Identificar las actividades didácticas adecuadas para la activación de las operaciones mentales de planeación, transcripción y edición de textos.

- Identificar las principales funcionalidades y los usos de las herramientas tecnológicas que influyen en el desarrollo de las habilidades escriturales.

- Ponderar los principales progresos de los estudiantes en la calidad de sus textos al finalizar el curso. 
Comunicación, redes, aprendizaje y desarrollo institucional y social

\section{Metodología}

La experiencia que se presenta en este estudio se caracteriza por ser una investigación-acción con un análisis descriptivo-cualitativo (Maxwell, 2012) y con un enfoque de investigación-acción crítica participativa (Kemmis, Wilkinson, Edwards-Groves, Hardy, Grootenboer y Bristol, 2013) sobre los resultados obtenidos a partir del proceso metodológico planteado en el curso. Para ello, se identificarán las diferentes condiciones que hicieron posible el funcionamiento del aula remota de escritura en el programa Comunicación Oral y Escrita del periodo 2014-I en relación con el mejoramiento de las habilidades escriturales en los estudiantes.

\section{Participantes}

En este curso, participaron 101 estudiantes de la sede de Arauca, 40 estudiantes de la sede Bogotá y 15 estudiantes de la sede Caribe, para 156 alumnos, todos de diferentes programas de formación en pregrado.

\section{Instrumentos}

Para observar y evaluar el proceso escritural argumentativo de los estudiantes en el curso, se contó con los siguientes elementos instrumentales:

- Examen inicial (prueba formativa): se planteó y diseñó para el curso una prueba inicial con un modelo ecológico (Bronfenbrenner, 1987), en el que se permitía evaluar reflexivamente los conocimientos previos de los estudiantes antes de iniciar el curso. La evaluación consistió en indagar y revisar conceptos sobre lenguaje, comunicación, lectura, escritura, lógica y argumentación (anexo 1).

- El regalo de la escritura: cómo aprender a escribir (Flórez y Cuervo, 2005): compilación y actualización de diversos materiales que estimulan la comprensión sobre lo que es "escribir bien" y “cómo" se logra ese propósito, con el uso herramientas y estrategias que apoyan la composición de diferentes tipos de texto. Su metodología incluye cuatro importantes subprocesos a la hora de escribir: 1) planeación, 2) transcripción, 3) revisión y 4) edición.

- Rejillas de revisión de textos argumentativos: para llevar a cabo el subproceso de revisión en la escritura de las primeras versiones de los textos elaborados por los estudiantes, se emplearon dos rejillas de chequeo. La primera rejilla, referenciada y 
adaptada por Cuervo y Flórez (2005), explora siete aspectos: 1) lógica, que se refiere el aspecto argumentativo; 2) claridad, que revisa el desarrollo coherente del texto; 3) léxico, que hace hincapié en observar el uso y significado de las palabras en el texto; 4) audiencia, que observa la voz del escrito; 5) energía, con la que se escribe el texto; 6) elaboración, desarrollo detallado del texto; y 7) mecánicas, que se refiere la ortografía, la gramática y la puntuación (anexo 2). La segunda rejilla (Milian, 1996, citado en Camps y Ribas, 2000), presenta pautas para desarrollar la revisión de un texto argumentativo, analizando elementos de propósito, audiencia, presentación de la tesis en el texto, tipo, cantidad, calidad de los argumentos y organización de estos en el texto (anexo 2). Se aclara que estos elementos se tendrán en cuenta en el apartado de resultados para analizar la categoría de producto.

- Evaluación final: que efectúa el Centro de Español de la Universidad de los Andes en 2014. Examen de las actitudes argumentativas desarrolladas por los estudiantes al finalizar el curso, a partir de un ejercicio de escritura planteado desde la lectura de tres documentos: una noticia y dos columnas de opinión, frente al tema de adopción de niños por parejas del mismo sexo. Los estudiantes debían realizar 1) planeación de un texto argumentativo presentando tema, tesis, audiencia, propósito y exponiendo los posibles argumentos y 2) desarrollar el texto argumentativo (anexo 3).

\section{Procedimiento}

La metodología de esta experiencia académica se relacionó con la instrucción de los procesos escriturales de manera virtual a través de videoconferencia (compartiendo escritorio), manejo de la plataforma Blackboard y comunicación por el correo electrónico y tutorial presencial con el apoyo de tutores en cada una de las sedes, aspectos que se pueden considerar paralelamente como instrumentos institucionales, tecnológicos (de presagio) y de didáctica (proceso-producto).

De igual manera, la estructura metodológica del curso se basó en el enfoque de la escritura como proceso (Flórez y Cuervo, 2005), con la producción de textos académicos orientados hacia la argumentación. Para cumplir con este propósito, se realizaron las etapas descritas en tabla 9.1.

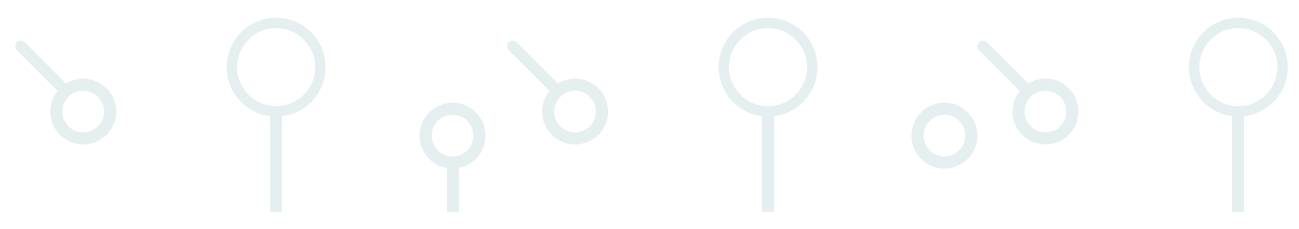




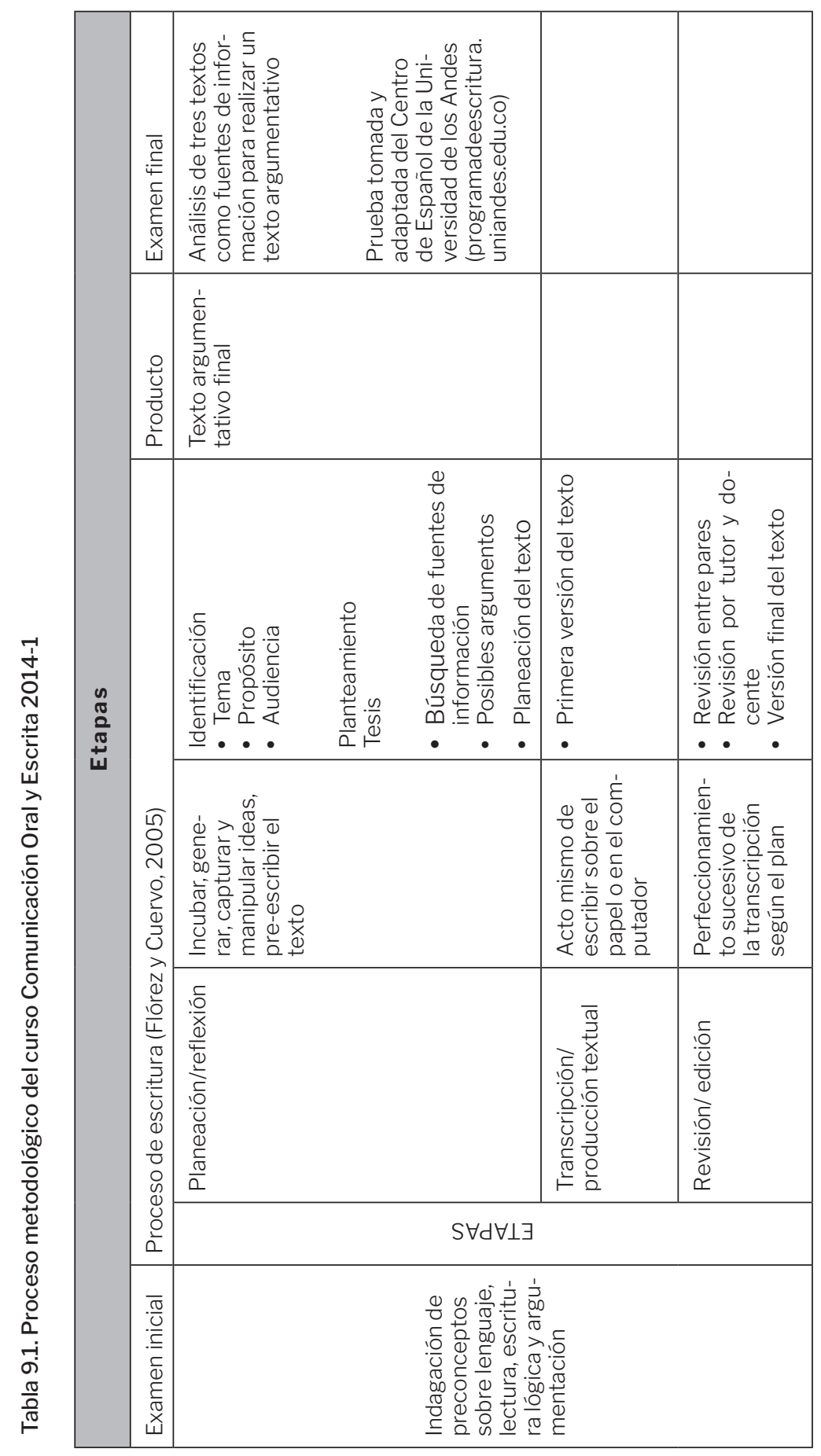




\begin{tabular}{|c|c|c|c|c|c|c|}
\hline & 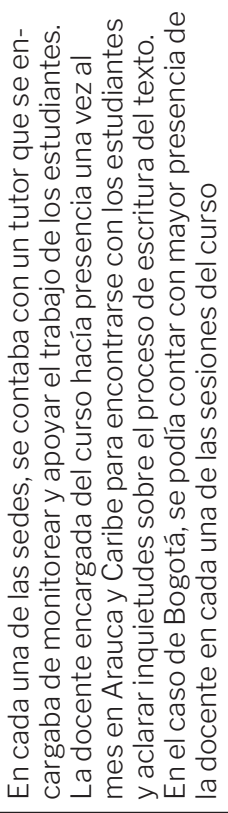 & 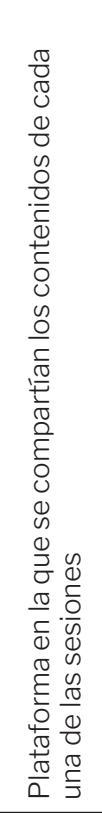 & 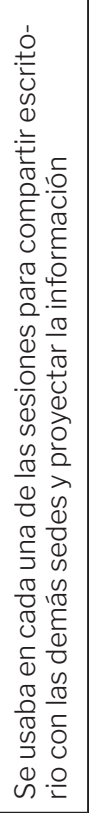 & 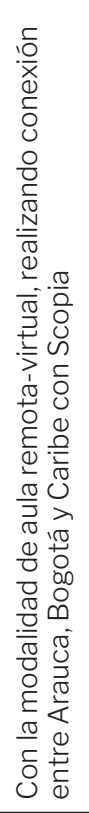 & 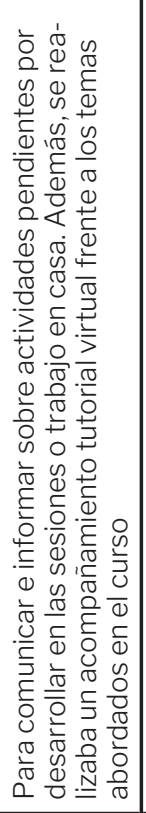 & 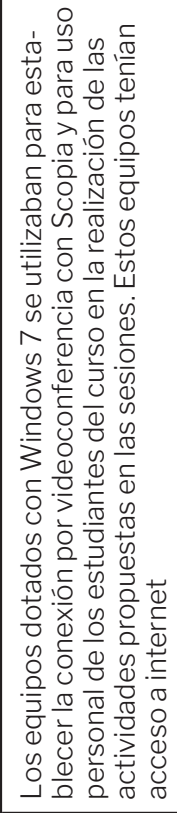 \\
\hline$\stackrel{\pi}{\omega}$ & 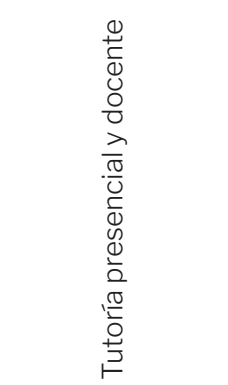 & $\begin{array}{l}\frac{D}{\pi} \\
\frac{0}{0} \\
\frac{d}{u} \\
\frac{\pi}{0}\end{array}$ & 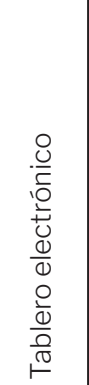 & 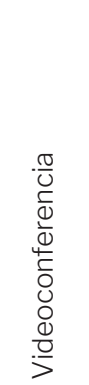 & 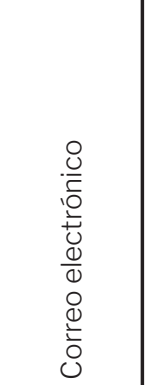 & 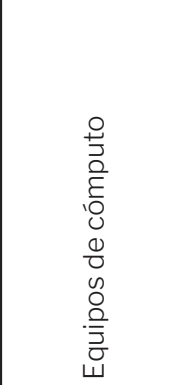 \\
\hline & 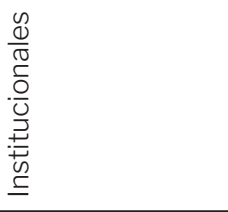 & \multicolumn{5}{|l|}{ 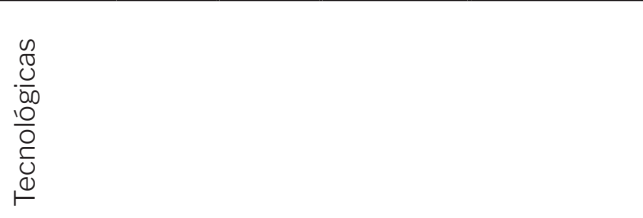 } \\
\hline & \multicolumn{6}{|c|}{ 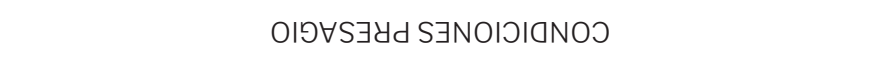 } \\
\hline
\end{tabular}




\section{Presagio}

En relación con esta categoría de condiciones de contexto, el acompañamiento docente se realizó en 100 \% de las 27 sesiones programadas en el curso, de manera presencial y virtual en Bogotá, estableciendo la conexión con Arauca y Caribe por medio de la videoconferencia. Este proceso tuvo un acompañamiento en paralelo de tutores idóneos, quienes, en cada una de las sedes, apoyaban y monitoreaban de manera presencial el trabajo de los estudiantes. Esta tutoría se llevó a cabo en 80 \% de las sesiones del curso, ya que el desarrollo de las clases fue principalmente efectuado por el docente, y 20 \% fuera del aula, que incluyó procesos de retroalimentación personal y virtual mediante el correo electrónico.

Conforme al compromiso de la universidad como institución, se determina en 90 \%, catalogando este compromiso en el préstamo de las instalaciones y su adecuación para el desarrollo de la clase, ya que ocasionalmente se presentaban disrupciones en las sesiones, porque las aulas no contaban con los dispositivos electrónicos aptos para realizar la videoconferencia o los estudiantes debían desplazarse a otras aulas con las adecuaciones medianamente apropiadas para realizar la conexión (figura 9.1).

Figura 9.1. Acompañamiento docente y tutorial del curso Comunicación Oral y Escrita 2014-1.

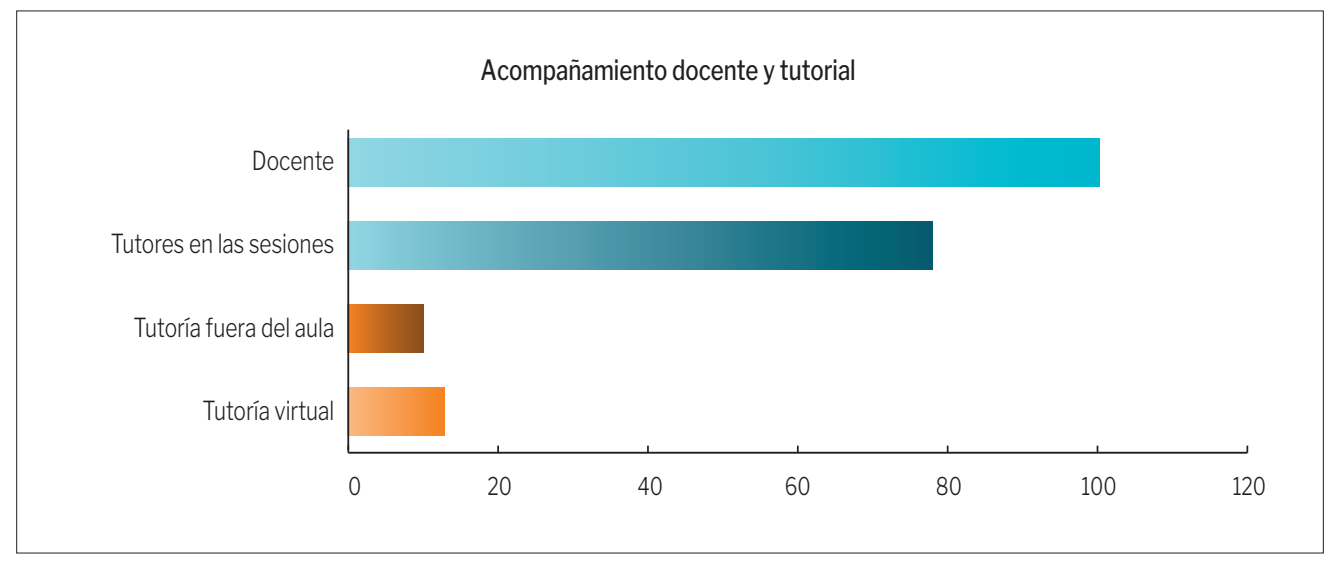

Fuente: Elaboración propia.

Con respecto al componente tecnológico que se manejó en el curso, se describe a continuación las herramientas con las que se contó, su uso y las consideraciones a nivel positivo o negativo de su utilización. 
Tabla 9.2. Entorno y herramientas tecnológicas del curso

\begin{tabular}{|c|c|c|c|}
\hline $\begin{array}{l}\text { Herramientas } \\
\text { tecnológicas }\end{array}$ & Uso & $\begin{array}{l}\text { Porcentaje } \\
\text { de efectividad } \\
\text { en su uso }\end{array}$ & $\begin{array}{l}\text { Aspectos positivos } \\
\text { o negativos de uso }\end{array}$ \\
\hline Blackboard & $\begin{array}{l}\text { Plataforma en la que se } \\
\text { compartían los conteni- } \\
\text { dos de cada una de las } \\
\text { sesiones y ocasional- } \\
\text { mente se desarrollaban } \\
\text { foros con la interacción } \\
\text { de los estudiantes, con- } \\
\text { cretando ideas y el desa- } \\
\text { rrollo de sus habilidades } \\
\text { cognitivo/comunicativas } \\
\text { como la escritura }\end{array}$ & $60 \%$ & $\begin{array}{l}\text { El acceso por parte de los estudian- } \\
\text { tes a la plataforma fue aceptable, ya } \\
\text { que ingresaban solo cuando debían } \\
\text { revisar el material o contenido de } \\
\text { la clase. Faltó mayor motivación } \\
\text { del manejo de esta herramienta de } \\
\text { forma interactiva, con una adecua- } \\
\text { ción más didáctica por parte de la } \\
\text { institución }\end{array}$ \\
\hline $\begin{array}{l}\text { Tablero } \\
\text { electrónico }\end{array}$ & $\begin{array}{l}\text { Se usaba en cada una de } \\
\text { las sesiones para com- } \\
\text { partir escritorio con las } \\
\text { demás sedes y proyectar } \\
\text { la información }\end{array}$ & $80 \%$ & $\begin{array}{l}\text { Entre los aspectos positivos, se } \\
\text { señala la posibilidad de que los } \\
\text { estudiantes siguieran en línea y } \\
\text { en tiempo real la exposición de los } \\
\text { contenidos durante las sesiones. En } \\
\text { cuanto a lo negativo, se hace refe- } \\
\text { rencia a las interferencias digitales } \\
\text { que se presentaban ocasionalmen- } \\
\text { te en proyectar la información, debi- } \\
\text { do a la rudimentariedad de algunos } \\
\text { equipos de cómputo }\end{array}$ \\
\hline $\begin{array}{l}\text { Video- } \\
\text { conferencia }\end{array}$ & $\begin{array}{l}\text { Con la modalidad de aula } \\
\text { remota-virtual, realizan- } \\
\text { do conexión entre Arau- } \\
\text { ca, Bogotá y Caribe }\end{array}$ & $90 \%$ & $\begin{array}{l}\text { La videoconferencia permitía } \\
\text { realizar una comunicación de la } \\
\text { información en tiempo real, pero } \\
\text { ocasionalmente se vio interferida } \\
\text { por dificultades en la red de internet } \\
\text { (intermitencia) o la latencia en esta- } \\
\text { blecer el enlace }\end{array}$ \\
\hline $\begin{array}{l}\text { Correo } \\
\text { electrónico }\end{array}$ & $\begin{array}{l}\text { Para comunicar e infor- } \\
\text { mar sobre actividades } \\
\text { pendientes a desarrollar } \\
\text { en las sesiones o trabajo } \\
\text { en casa. Además, se } \\
\text { realizaba un acompaña- } \\
\text { miento tutorial virtual } \\
\text { frente a los temas abor- } \\
\text { dados en el curso }\end{array}$ & $90 \%$ & $\begin{array}{l}\text { Fue una herramienta de comuni- } \\
\text { cación efectiva que permitió una } \\
\text { constante comunicación con los } \\
\text { estudiantes para informar sobre } \\
\text { actividades pendientes, recordar } \\
\text { los contenidos que se revisarían en } \\
\text { las sesiones del curso y monitorear/ } \\
\text { retroalimentar los procesos de } \\
\text { escritura en diferentes momentos }\end{array}$ \\
\hline $\begin{array}{l}\text { Equipos de } \\
\text { cómputo }\end{array}$ & $\begin{array}{l}\text { Los equipos dotados } \\
\text { con Windows } 7 \text { se uti- } \\
\text { lizaban para establecer } \\
\text { la conexión por video- } \\
\text { conferencia con Scopia } \\
\text { y para uso personal de } \\
\text { los estudiantes del curso } \\
\text { en la realización de las } \\
\text { actividades propuestas } \\
\text { en las sesiones. Estos } \\
\text { equipos tenían acceso a } \\
\text { internet }\end{array}$ & $90 \%$ & $\begin{array}{l}\text { De los equipos disponibles en Bo- } \\
\text { gotá, fallaban al menos tres de ellos, } \\
\text { porque no disponían de acceso a } \\
\text { internet, situación que afectaba el } \\
\text { trabajo personal de los estudiantes } \\
\text { que los utilizaban. En relación con } \\
\text { el equipo que se utilizaba para es- } \\
\text { tablecer la conexión por videocon- } \\
\text { ferencia con las demás sedes, se } \\
\text { encontraba en buenas condiciones } \\
\text { para su utilización }\end{array}$ \\
\hline
\end{tabular}

Fuente: Elaboración propia. 


\section{El proceso}

Como se describió en la metodología, el curso se basó en el enfoque de la escritura como proceso haciendo hincapié en la producción de textos argumentativos y siguiendo los aportes teóricos planteados en Flórez y Cuervo (2005). A continuación, se presenta la tabla 9.3, que contiene las principales etapas en que se desarrolló este proceso, caracterizando de manera general el desempeño de los estudiantes en estas actividades.

Tabla 9.3. Didáctica en el proceso de escritura (planeación)

\begin{tabular}{|c|c|c|}
\hline & & $\begin{array}{l}\text { Desarrollo y cumplimiento de las etapas } \\
\text { Proceso de escritura (Flórez y Cuervo, 2005) }\end{array}$ \\
\hline \multirow{6}{*}{ 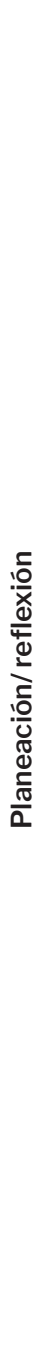 } & \multirow{3}{*}{ 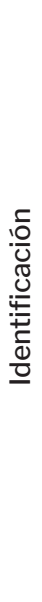 } & $\begin{array}{l}\text { Tema : Para los estudiantes, fue flexible identificar el tema sobre el que realizarían el texto } \\
\text { argumentativo, porque abordaron contenidos relacionados con sus programas de forma- } \\
\text { ción o de interés personal. En este ejercicio, se logró una comprensión de } 60 \% \text { (alrededor } \\
\text { de } 24 \text { estudiantes), mientras que } 40 \text { \% identificó un tema, pero les fue difícil especificar } \\
\text { un solo aspecto por tratar. De igual manera, dentro de este último porcentaje, también se } \\
\text { presentaron cuatro casos contrarios en los que los estudiantes lo plantearon de mane- } \\
\text { ra muy general, caracterizándose como una vaguedad o poca claridad en el abordaje del } \\
\text { tema propuesto }\end{array}$ \\
\hline & & $\begin{array}{l}\text { Propósito: A los estudiantes se les dificultó comprender que el propósito iba ligado al tipo } \\
\text { de texto que se desarrollaría (argumentativo). Sin embargo, } 53 \text { \% (relacionado con } 22 \text { es- } \\
\text { tudiantes aproximadamente) identificó la intención como informar y argumentar, mientras } \\
\text { que } 47 \% \text { lo correspondió con otros aspectos, como describir, entender, generar situacio- } \\
\text { nes de conciencia frente al tema, etc. }\end{array}$ \\
\hline & & $\begin{array}{l}\text { Audiencia : Fue clara la caracterización de este aspecto precisando la especificidad en } \\
\text { identificar posibles actores o lectores a quienes poder dirigir el tema o texto que referen- } \\
\text { ció } 65 \% \text { ( } 26 \text { estudiantes, aproximadamente). El } 35 \% \text { de los participantes no particularizó } \\
\text { la audiencia o simplemente no la detectó }\end{array}$ \\
\hline & \multirow{3}{*}{ 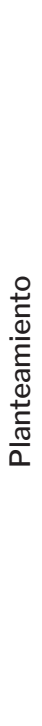 } & $\begin{array}{l}\text { Tesis : La comprensión de la estructuración de la tesis fue de } 68 \text { \% (alrededor de } 28 \text { es- } \\
\text { tudiantes), planteándola de manera interesante, específica y manejable y respetando la } \\
\text { estructura tema + verbo + comentario corto. Un } 16 \% \text { de los estudiantes presentó dificulta- } \\
\text { des en especificarla, porque desarrollaron comentarios amplios y así perdieron la claridad } \\
\text { en entender qué abordarían en el tema escogido, } 16 \% \text { no planteó una tesis clara, desligan- } \\
\text { do totalmente la estructura estudiada en el curso }\end{array}$ \\
\hline & & $\begin{array}{l}\text { Búsqueda de fuentes de información : Los estudiantes realizaron búsqueda de informa- } \\
\text { ción para sustentar sus textos argumentativos, consultando las siguientes fuentes: blogs } \\
\text { académicos en línea y páginas web ( } 40 \% \text { ), artículos científicos y artículos de periódico } \\
\text { en internet ( } 36 \% \text { ), libros y ensayos académicos (14 \%) y videos informativos (10 \%). En la } \\
\text { tabla } 9.4, \text { se precisa cómo se distribuyó la búsqueda de información conforme al número } \\
\text { de estudiantes participantes en el curso y las notas obtenidas en la actividad de reseñas } \\
\text { bibliográficas }\end{array}$ \\
\hline & & $\begin{array}{l}\text { Posibles argumentos / Planeación del texto: El } 65 \text { \% de los estudiantes (alrededor de } 26 \\
\text { participantes) logró desarrollar un adecuado bosquejo o planear una posible estructura } \\
\text { para su texto; aunque no propusieron ideas totalmente argumentativas, incluyeron aspec- } \\
\text { tos de información y descripción. Un } 22.5 \text { \% (entre } 9 \text { estudiantes) realizó planeaciones } \\
\text { aceptables con pocos componentes argumentativos, pero más informativos y descripti- } \\
\text { vos. El } 7.5 \% \text { ( } 3 \text { participantes) elaboró una planeación totalmente informativa, } 2.5 \text { \% (apro- } \\
\text { ximadamente } 1 \text { estudiante) no entendió el ejercicio, introduciendo en el bosquejo párrafos } \\
\text { amplios de información sobre el tema y el } 2.5 \text { \% restante no entregó la actividad }\end{array}$ \\
\hline
\end{tabular}

Fuente: Elaboración propia. 
Especificando en el subproceso de planeación las actividades de búsqueda de fuentes de información, se relaciona en la tabla 9.4 el número de estudiantes que presentó reseñas bibliográficas de las fuentes, distribuyendo las notas obtenidas en esta actividad conforme a la cantidad y calidad en la búsqueda de la información.

Tabla 9.4. Subproceso de planeación, actividad de búsqueda y reseña de fuentes de información

\begin{tabular}{|c|c|c|}
\hline Distribución de notas & Calidad de actividad & \# estudiantes (\%) \\
\hline De 0.0 a 1.0 & $\begin{array}{l}\text { Estudiantes que no consultaron ninguna fuente de } \\
\text { información }\end{array}$ & $1(2.5)$ \\
\hline De 1.0 a 2.0 & $\begin{array}{l}\text { Estudiantes que consultaron al menos una fuente de } \\
\text { información en internet }\end{array}$ & $1(2.5)$ \\
\hline De 2.0 a 3.0 & $\begin{array}{l}\text { Estudiantes que consultaron entre dos a tres fuen- } \\
\text { tes de información en internet }\end{array}$ & $1(2.5)$ \\
\hline De 3.0 a 4.0 & $\begin{array}{l}\text { Estudiantes que consultaron mínimo cuatro fuentes } \\
\text { de información en internet }\end{array}$ & $12(30)$ \\
\hline De 4.0 a 5.0 & $\begin{array}{c}\text { Estudiantes que consultaron cinco fuentes } \\
\text { de información, incluso artículos, libros, ensayos } \\
\text { y páginas web }\end{array}$ & $25(62.5)$ \\
\hline
\end{tabular}

Fuente: Elaboración propia.

Para el subproceso de revisión entre pares, tutorial y docente, se utilizaron dos rejillas de evaluación (reseñadas en el apartado metodológico), que permitieron analizar la estructura de las versiones preliminares y finales de los textos en los aspectos de forma, contenido y argumentación. A continuación, se presentan los resultados generales teniendo en cuenta los elementos enunciados en una de dichas rejillas (Dalton y Dalton, 1990), que recopila lo más importante que se observó en los textos. La segunda rejilla se abordará en el apartado de producto, ya que precisa más detalladamente los aspectos argumentativos que se evaIuaron (tabla 9.5). 
Tabla 9.5. Didáctica del proceso de escritura, transcripción, producción textual, revisión y edición

\begin{tabular}{|c|c|c|}
\hline & & $\begin{array}{l}\text { Desarrollo y cumplimiento de las etapas } \\
\text { Proceso de escritura (Flórez y Cuervo, 2005) }\end{array}$ \\
\hline 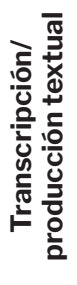 & $\begin{array}{l}\text { Primera } \\
\text { versión } \\
\text { del texto }\end{array}$ & $\begin{array}{l}\text { Los estudiantes realizaron su primera versión textual del escrito argu- } \\
\text { mentativo, conforme a las decisiones previas tomadas en el subpro- } \\
\text { ceso de planeación. Como correspondió a un texto preliminar, todos } \\
\text { (100 \% de los textos) presentaban errores ortográficos, gramáticos, de } \\
\text { puntuación y, ante todo, de redacción y desarrollo coherente de algu- } \\
\text { nos argumentos. Por ello, este paso se complementó con una revisión } \\
\text { entre pares y otra por parte del tutor, con el fin de mejorar estos aspec- } \\
\text { tos para la versión final del texto argumentativo }\end{array}$ \\
\hline \multirow{3}{*}{ 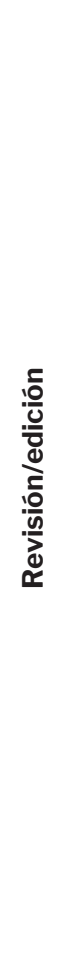 } & $\begin{array}{l}\text { Revisión } \\
\text { entre pares }\end{array}$ & $\begin{array}{l}\text { Este ejercicio se planteó con el fin de realizar una retroalimentación en } \\
\text { paralelo de pares. Se observó que los comentarios de los estudiantes } \\
\text { de Bogotá lograron enfocarse en aspectos de ortografía y puntuación } \\
\text { en } 50 \% \text {, coherencia en la redacción de las ideas en } 30 \% \text {, claridad de } \\
\text { los argumentos planteados en } 15 \% \text { y manejo de normas de referencia- } \\
\text { ción (APA) en } 5 \%\end{array}$ \\
\hline & $\begin{array}{l}\text { Revisión por } \\
\text { tutores y do- } \\
\text { cente }\end{array}$ & $\begin{array}{l}\text { Se desarrolló de igual manera una revisión por parte de los tutores y } \\
\text { el docente en los aspectos de lógica del texto con la tesis y los argu- } \\
\text { mentos planteados, claridad y coherencia en la redacción de las ideas, } \\
\text { organización en el desarrollo de los argumentos, caracterización del } \\
\text { propósito del texto, ortografía, puntuación y manejo de citación/refe- } \\
\text { renciación con normas APA. Aspectos que se precisan de manera más } \\
\text { puntual en la tabla } 9.6\end{array}$ \\
\hline & $\begin{array}{l}\text { Versión final } \\
\text { del texto }\end{array}$ & $\begin{array}{l}\text { En este apartado, se relaciona el perfeccionamiento del texto conforme } \\
\text { a la primera versión revisada, exponiendo que alrededor de } 17 \text { estudian- } \\
\text { tes ( } 42.5 \% \text { ) mejoraron y ajustaron adecuadamente para el texto final } \\
\text { aspectos de contenido (argumentos y organización del texto), cohe- } \\
\text { rencia y cohesión, forma-mecánica (ortografía y puntuación) y referen- } \\
\text { ciación (normas APA). Veintidós estudiantes (correspondiente a } 55 \text { \%) } \\
\text { realizaron ajustes al texto en forma-mecánica (errores ortográficos y de } \\
\text { puntuación) y ajustes aceptables al aspecto argumentativo, desarrollo } \\
\text { del texto y manejo de normas de referenciación (APA). Finalmente, } \\
2.5 \% \text { restante (1 estudiante) no mejoró el texto conforme a las obser- } \\
\text { vaciones de la revisión y no realizaron ajustes. En la tabla 9.6, se relacio- } \\
\text { nan estos resultados conforme a los intervalos de notas obtenidos por } \\
\text { los participantes en el producto del curso (texto final) }\end{array}$ \\
\hline
\end{tabular}

Fuente: Elaboración propia.

Explicitando la actividad de revisión en la versión preliminar del texto por parte del tutor y docente, se describe de manera general (porcentualmente) el panorama obtenido en el chequeo, teniendo en cuenta los criterios dictados en la rejilla de evaluación mencionada en el párrafo anterior (tabla 9.6). 
Tabla 9.6. Elementos generales observados en el subproceso de revisión del texto

\begin{tabular}{|c|c|}
\hline Lista de chequeo de los siete aspectos más importantes & $\begin{array}{l}\text { Porcentaje } \\
\text { de textos }\end{array}$ \\
\hline \multicolumn{2}{|l|}{ 1. Lógica } \\
\hline ¿Existe una tesis o enunciado central? & 60 \\
\hline ¿Tienen secuencia lógica los párrafos? & 57.5 \\
\hline ¿Tienen secuencia lógica las oraciones? & 57.5 \\
\hline ¿Existen hechos, datos específicos, detalles, razones que apoyen la tesis? & 55 \\
\hline \multicolumn{2}{|l|}{ 2. Claridad } \\
\hline ¿Existen lugares en el escrito que no tienen sentido? & 50 \\
\hline ¿Existen oraciones que no son claras? & 42.5 \\
\hline ¿Se enuncian las ideas de manera simple? & 97.5 \\
\hline ¿Se define con claridad la terminología? & 97.5 \\
\hline \multicolumn{2}{|l|}{ 3. Léxico } \\
\hline ¿Predominan los verbos activos? & 100 \\
\hline ¿Predominan los verbos pasivos? & 10 \\
\hline $\begin{array}{l}\text { ¿Hay lugares donde una palabra podría reemplazar varias? } \\
\text { ¿Hay palabras mal usadas? }\end{array}$ & 40 \\
\hline ¿Se limitan las palabras a sonar bien en vez de significar algo? & 15 \\
\hline ¿Se han usado sinónimos de manera apropiada en vez de simplemente repetir palabras? & 40 \\
\hline \multicolumn{2}{|l|}{ 4. Audiencia } \\
\hline ¿Se identifica la audiencia? & 15 \\
\hline ¿Es consistente la voz del escrito? & 60 \\
\hline ¿Es coherente el léxico con la audiencia? & 60 \\
\hline \multicolumn{2}{|l|}{ 5. Energía } \\
\hline ¿Tiene energía el tema? & 60 \\
\hline ¿Tiene energía el escrito? & 40 \\
\hline ¿Tiene energía el léxico? & 40 \\
\hline \multicolumn{2}{|l|}{ 6. Elaboración } \\
\hline ¿Se exploró el tema desde todos los ángulos? & 40 \\
\hline ¿La discusión está detallada y desarrollada? & 40 \\
\hline \multicolumn{2}{|l|}{ 7. Mecánica } \\
\hline ¿Hay errores de ortografía? & 90 \\
\hline ¿Hay errores de gramática? & 90 \\
\hline ¿Es adecuada la puntuación? & 90 \\
\hline $\begin{array}{l}\text { ¿Se presentan citaciones durante el cuerpo del texto para apoyar la información presenta- } \\
\text { da? }\end{array}$ & 90 \\
\hline ¿Se referencian al final del texto todas las fuentes citadas durante el cuerpo del texto? & 90 \\
\hline
\end{tabular}

Fuente: Dalton y Dalton (1990). 


\section{Producto}

Antes de iniciar el curso, los estudiantes fueron evaluados con el propósito de indagar sus conocimientos previos sobre lenguaje, comunicación, lectura, lógica y argumentación. De igual manera, al finalizar el curso, se les planteó otra evaluación más concreta en torno a la producción de textos argumentativos, siguiendo los pasos planteados en la escritura como proceso. A continuación, se determinan los aspectos evaluados en cada una de las pruebas, presentando los resultados de manera cualitativa (figura 9.7).

Tabla 9.7. Elementos observados en las pruebas inicial y final del curso

\begin{tabular}{|c|c|c|}
\hline & $\begin{array}{l}\text { Aspectos } \\
\text { evaluados }\end{array}$ & Resultados \\
\hline \multirow{5}{*}{ 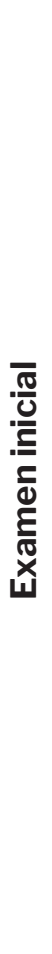 } & $\begin{array}{l}\text { Conceptos sobre } \\
\text { lenguaje, comu- } \\
\text { nicación, lógica y } \\
\text { argumentación }\end{array}$ & $\begin{array}{l}\text { Se observó que los estudiantes precisaban aceptablemente en } \\
36 \text { \% (13 pruebas) los conceptos relacionados con lenguaje, co- } \\
\text { municación, lectura y otros enfocados en la gramática, ya que las } \\
\text { definiciones determinadas a estos conceptos presentaban algunos } \\
\text { vacíos que solo se concretan con aspectos más teóricos sobre estos } \\
\text { conceptos. Sobre los términos de lógica y argumentación, } 65 \text { \% (26 } \\
\text { pruebas) acertó en la comprensión de estos explicando que tienen } \\
\text { que ver con sustentar una posición frente a un tema }\end{array}$ \\
\hline & $\begin{array}{l}\text { Sintaxis de } \\
\text { oraciones }\end{array}$ & $\begin{array}{l}\text { El } 100 \text { \% de los estudiantes identificó adecuadamente los elemen- } \\
\text { tos cambiantes en tres oraciones, determinando cuándo la palabra } \\
\text { que se cambiaba dentro de la oración actuaba como adjetivo o como } \\
\text { otra palabra de complemento de información, rescatando de igual } \\
\text { manera la relación entre sintaxis y su influencia en la semántica de } \\
\text { las oraciones }\end{array}$ \\
\hline & Ortografía & $\begin{array}{l}\text { El } 72,5 \% \text { de los estudiantes (29 participantes) no tuvo inconvenien- } \\
\text { tes en identificar los errores ortográficos en } 17 \text { palabras propuestas } \\
\text { para corregir. El } 27.5 \% \text { restante solo presentó dificultades en reco- } \\
\text { nocer los errores en una o dos palabras }\end{array}$ \\
\hline & $\begin{array}{l}\text { Elementos co- } \\
\text { hesivos }\end{array}$ & $\begin{array}{l}\text { El } 100 \text { \% de los estudiantes identificó y complementó dentro de un } \\
\text { párrafo los enlaces cohesivos apropiados para dar coherentemente } \\
\text { la cohesión de las ideas }\end{array}$ \\
\hline & $\begin{array}{l}\text { Comprensión } \\
\text { de lectura }\end{array}$ & $\begin{array}{l}\text { El } 67,5 \% \text { de los participantes (27 estudiantes) presentó respuestas } \\
\text { correctas frente a la lectura de dos enunciados y } 32.5 \% \text { (13 estu- } \\
\text { diantes) del resto de participantes solo obtuvo mal una respuesta } \\
\text { con respecto a los dos enunciados abordados en la prueba }\end{array}$ \\
\hline
\end{tabular}




\begin{tabular}{|c|c|c|}
\hline & Aspectos evaluados & Resultados \\
\hline \multirow{6}{*}{ } & $\begin{array}{l}\text { Planteamiento de la tesis o enunciado } \\
\text { central }\end{array}$ & $\begin{array}{l}\text { El } 97.5 \text { \% (39 estudiantes) planteó una tesis via- } \\
\text { ble, conforme a los elementos que la componen } \\
\text { (tema + verbo + comentario), teniendo en cuenta } \\
\text { la información proporcionada en los textos faci- } \\
\text { litados como fuentes de información dentro de } \\
\text { la prueba. El } 2.5 \% \text { de participantes (1 estudiante) } \\
\text { no presentó la prueba final porque no asistió a la } \\
\text { sesión }\end{array}$ \\
\hline & $\begin{array}{l}\text { Planeación del texto a escribir a partir } \\
\text { de las tres fuentes facilitadas }\end{array}$ & $\begin{array}{l}\text { El } 97.5 \% \text { de los estudiantes elaboró una pla- } \\
\text { neación del texto antes de realizar el ejercicio de } \\
\text { escritura como tal. Entre este porcentaje, } 95 \% \\
\text { (38 estudiantes) tuvo un proceso de planeación } \\
\text { adecuado, identificando elementos como tema, } \\
\text { propósito, audiencia y especificación de una po- } \\
\text { sible estructura de desarrollo de los argumentos } \\
\text { por tratar en el texto }\end{array}$ \\
\hline & $\begin{array}{l}\text { Secuencia y desarrollo lógico de los } \\
\text { argumentos } \\
\text { Secuencia lógica de los párrafos y } \\
\text { oraciones }\end{array}$ & $\begin{array}{l}\text { En general, todos los participantes realizaron } \\
\text { una adecuada organización y desarrollo de los } \\
\text { argumentos dentro de los párrafos del texto, evi- } \\
\text { denciando argumentos válidos, presentando un } \\
\text { hilo conductor en su desarrollo, exponiendo un } \\
\text { texto con la tesis como inicio y en la parte final } \\
\text { los apartados concluyentes. En este ejercicio, } \\
62.5 \% \text { de los estudiantes (correspondiente a } 25 \\
\text { participantes) tuvo un mejor desempeño respec- } \\
\text { to de } 35 \% \text { (14 participantes) }\end{array}$ \\
\hline & $\begin{array}{l}\text { Existencia de hechos, datos especí- } \\
\text { ficos, detalles y razones que apoyen } \\
\text { la tesis }\end{array}$ & $\begin{array}{l}\text { Estos elementos se evidenciaron conforme a la } \\
\text { información leída en las fuentes facilitadas como } \\
\text { soporte para la realización del texto argumenta- } \\
\text { tivo y de manera general todos los estudiantes } \\
\text { presentaron una adecuada presentación de } \\
\text { información que sustentara los argumentos } \\
\text { propuestos, aunque este ejercicio fue mejor en } \\
62.5 \% \text { de los participantes }\end{array}$ \\
\hline & Conclusiones en el texto & $\begin{array}{l}\text { Todos los textos presentaron un apartado } \\
\text { concluyente; sin embargo, } 62.5 \% \text { de los parti- } \\
\text { cipantes logró establecer conclusiones claras y } \\
\text { consistentes frente a la tesis propuesta }\end{array}$ \\
\hline & $\begin{array}{l}\text { Manejo de citación y normas de refe- } \\
\text { renciación en APA }\end{array}$ & $\begin{array}{l}\text { Al final del curso, hubo una comprensión del } \\
\text { manejo de normas APA como una forma de } \\
\text { referenciación y citación; pero, en todos los } \\
\text { estudiantes, faltó precisión en abordarlo dentro } \\
\text { del texto. Alrededor de } 25 \% \text { de los participantes } \\
\text { logró realizar el uso de estas normas dentro del } \\
\text { texto }\end{array}$ \\
\hline
\end{tabular}

Fuente: Elaboración propia. 
Comunicación, redes, aprendizaje y desarrollo institucional y social

También, se presenta en este apartado la relación del perfeccionamiento en los textos finales, presentando los resultados con respecto a las notas obtenidas por los estudiantes en este producto (tabla .98) y en relación con los criterios establecidos en la rejilla 2 (Milian, 1994, citado en Camps y Ribas, 2000), que precisa aspectos de índole argumentativa (tablas 9.8 y 9.8 ).

Tabla 9.8. Subproceso de revisión/edición del texto final argumentativo

\begin{tabular}{|c|l|c|}
\hline Distribución de notas & \multicolumn{1}{|c|}{ Calidad del texto final } & $\begin{array}{c}\text { \# estudiantes } \\
\text { (\%) }\end{array}$ \\
\hline De 0.0 a 2.0 & $\begin{array}{l}\text { No mejoraron el texto conforme a las observaciones } \\
\text { de la revisión y no realizaron ajustes }\end{array}$ & $1(2.5)$ \\
\hline De 2.0 a 4.0 & $\begin{array}{l}\text { Realizaron ajustes al texto en forma-mecánica (erro- } \\
\text { res ortográficos y de puntuación) y ajustes acepta- } \\
\text { bles al aspecto argumentativo, desarrollo del texto y } \\
\text { manejo de normas de referenciación (APA) }\end{array}$ & 22 (55) \\
\hline De 4.0 a 5.0 & $\begin{array}{l}\text { Realizaron ajustes adecuados al texto en contenido } \\
\text { (argumentos y organización del texto) y forma-me- } \\
\text { cánica (ortografía y puntuación) }\end{array}$ & 17 (42.5) \\
\hline
\end{tabular}

Fuente: Elaboración propia.

\section{Análisis de resultados}

Conforme a los aspectos identificados, se puede describir de manera general las siguientes relaciones.

\section{Presagio}

El acompañamiento tutorial presencial es un complemento necesario que debe tenerse en cada curso desarrollado de manera virtual, porque apoya la comprensión de los contenidos abordados. Su asistencia a cada una de las sesiones presenciales contribuye a la retroalimentación de los procesos de escritura en los participantes del curso, pero es importante que los tutores sean reconocidos por los estudiantes como pares académicos con los que pueden contar, con los suficientes conocimientos en el campo disciplinar que apoyan y en el componente escritural (Varón y Moreno, 2009). En el curso de Comunicación Oral y Escrita, los tutores administraron contenidos y asesoría sobre el proceso de escritura de los estudiantes mediante el correo electrónico y de manera presencial, acompañaron a las sesiones remotas y ocasionalmente las dirigieron (Varón y Moreno, 2009). 
Tabla 9.9. Subproceso de revisión/edición del texto final argumentativo (Milian, 1994, citado en Camps y Ribas, 2000)

\begin{tabular}{|c|c|}
\hline 1. Elementos de la argumentación & Porcentaje de textos \\
\hline 1.1¿Queda claro el receptor del texto? & 15 \\
\hline 1.2 ¿Queda claro a quién queremos convencer? & 15 \\
\hline 1.3 ¿Queda claro quién escribe el texto? & 10 \\
\hline 1.4 ¿Definimos claramente nuestra tesis? & 60 \\
\hline 1.5 ¿Damos argumentos para justificarla? & 55 \\
\hline 1.6 ¿Aceptamos alguna opinión de los oponentes? & 15 \\
\hline \multicolumn{2}{|l|}{ Organización del texto. ¿Dónde aparece la tesis? } \\
\hline 2.1 Al inicio & 90 \\
\hline 2.2 Al final & 0 \\
\hline 2.3 Aparece más de una vez & 0 \\
\hline 2.4 No aparece & 10 \\
\hline \multicolumn{2}{|l|}{ ¿Cuántos argumentos hemos dado para defender nuestra opinión? } \\
\hline 2.5 Todos los de la lista de planificación & 66 \\
\hline 2.6 Unos cuantos & 30 \\
\hline 2.7 Un único argumento & 0 \\
\hline 2.8 Ninguno & 4 \\
\hline \multicolumn{2}{|l|}{ Tipos de argumentos } \\
\hline $\begin{array}{l}\text { 2.9 Hay argumentos basados en opiniones de algún científico } \\
\text { o de personalidades reconocidas en la materia }\end{array}$ & 65 \\
\hline 2.10 Hay argumentos justificados con datos objetivos o ejemplos & 65 \\
\hline 2.11 Los argumentos se justifican en nuestra experiencia personal & 20 \\
\hline 2.12 Los argumentos son opiniones personales no justificadas & 10 \\
\hline \multicolumn{2}{|l|}{ ¿Cómo se presentan los argumentos? } \\
\hline 2.13 Se presentan en un solo párrafo, uno detrás de otro & 65 \\
\hline 2.14 Hay argumentos en cada párrafo, con ejemplos y explicaciones & 25 \\
\hline 2.15 Hay elementos que marcan el orden de los argumentos & 25 \\
\hline $\begin{array}{l}\text { 2.16 Se contrastan los argumentos con los contraargumentos } \\
\text { en el mismo párrafo }\end{array}$ & 20 \\
\hline $\begin{array}{l}\text { 2.17 Los argumentos y los contraargumentos se presentan } \\
\text { en párrafos distintos }\end{array}$ & 10 \\
\hline
\end{tabular}

Fuente: Elaboración propia. 
En relación con el docente, su función consistió en configurar la naturaleza del ambiente de aprendizaje, caracterizándose como un par más avanzado que indagó e invitó a los estudiantes a participar y construir encuentros comunicativos sobre temas específicos en torno a los contenidos tratados en el curso. También, el docente actuó como un actor orientador en el proceso de escritura de los textos argumentativos, manteniendo su postura frente al objetivo y el enfoque propuestos en el curso (Varón y Moreno, 2009).

Pese a que la conexión por videoconferencia se presentó adecuadamente en la mayoría de las sesiones, ocasionalmente se presentaron dificultades, como interferencia, baja red en el enlace, problemas en compartir el contenido en tiempo real y seguir en línea la comunicación de la docente con los estudiantes, lo cual pudo posiblemente influir en la comprensión adecuada de la información compartida en algunas sesiones del curso y evidenciarse en un desarrollo claro de ciertas actividades planteadas.

El uso de la plataforma Blackboard fue exclusivamente solo para compartir contenidos del curso entre las sedes, pero hubiese sido más pertinente poder aprovechar un poco más esta herramienta de manera interactiva, contando con más apoyo por parte de los organismos administrativos en las aulas virtuales de la institución, siendo una estrategia adecuada para enriquecer el uso de esta herramienta virtual con los estudiantes.

El proceso tutorial por medio del correo electrónico enriqueció la forma de interactuar entre los estudiantes, el docente y los tutores, observando que este modo de comunicación, no solo se limitó a ser un medio para obtener las actividades por parte de los estudiantes y enviar la calificación, sino profundizar en una retroalimentación más personalizada, con un compartir de inquietudes y saberes entre estos actores. Se observó un mayor grado de confianza por parte de los estudiantes en poder preguntar y expresar sus dificultades en algunos de los ejercicios abordados, reconociéndose esto como el interés sobre los procesos de aprendizaje y caracterizándose como una charla escrita más amena.

\section{El proceso}

En cuanto a los procesos de escritura desarrollados en el curso, se pudo evidenciar una comprensión adecuada de cada una de las etapas en los estudiantes, aspecto observable en la precisión presentada desde el planteamiento de la tesis, con su identificación de las características principales que la componen (tema + comentario) (Flórez y Cuervo, 2005); la búsqueda de fuentes fidedignas de información, como documentos científicos, blogs académicos, artículos de periódicos confiables, entre otras; la planeación del texto; la propuesta de argumentos medianamente válidos para escribir (Sánchez, Serrano y Peña 2009); y la macroestructura del texto. 
Asimismo, desarrollar el curso con un enfoque de la escritura como proceso (Flórez y Cuervo, 2005) permitió que hubiese una claridad en los estudiantes en cumplir ciertas etapas para llegar al producto final. Esto consideró la estructuración organizada de las actividades que iban desarrollando paulatinamente para lograr el objetivo final, que consistió en la creación de una versión final de un texto argumentativo lo más adecuadamente posible.

\section{Producto}

En general, los textos finales obtenidos en el curso presentaron una adecuada estructuración y un desarrollo coherente de los argumentos. Los estudiantes comprendieron la importancia de plantear una tesis sobre la cual apoyar y mantener una posición y construir argumentos válidos apoyados por fundamentos teóricos (rescatados de fuentes de información fidedigna), que presenten un desarrollo coherente dentro de un texto para dar organización a la información presentada. Además, se rescata en los estudiantes la forma de observar y realizar el texto argumentativo, no como un escrito informativo, sino como un texto en el que es importante explicitar lo más claramente posible ideas críticas que se tienen frente a un tema. Esto se logró evidenciar en el texto final entregado y específicamente en el examen final propuesto.

\section{Discusión}

Del análisis de la información obtenida llama la atención la emergencia de las nuevas formas de interacción que se establecen entre profesores y estudiante. Como se señaló (De Vicente, 2005), el curso posee varios canales de comunicación directa con el docente, tutores y estudiantes y correo electrónico, a los que los miembros del curso pueden acudir en cualquier momento. Para la construcción de una comunidad de escritura, es de resaltar que los estudiantes sientan la necesidad de comunicarse con su profesor y que aprendan a utilizar cierto lenguaje "formal" para ello, incluso cuando escriben un correo electrónico o un chat (Matzat, 2004). Otro aspecto por destacar es la disposición permanente de recursos; que el estudiante pueda tener a disposición los contenidos del curso, las actividades, el diario de aprendizaje y otros recursos promueve el aprendizaje autónomo, que es uno de los ideales de la Universidad Nacional de Colombia (Rué, 2009).

En cuanto a los factores de tipo institucional, cabe destacar el esfuerzo de la Universidad Nacional de Colombia por dotar tanto a la sede Bogotá como a las sedes de presencia nacional de la infraestructura requerida para realizar este tipo de cursos, con lo cual muestra su interés por llegar a muchos lugares del país y así ampliar su cobertura sin descuidar la calidad de sus acciones. 
Sin embargo, se pudo constatar que es difícil forjar en los estudiantes de las sedes de presencia nacional un habitus (Bourdieu, 2005) para la construcción de conocimiento a través de cursos que estén soportados en las TIC. La mayoría espera formas tradicionales de transmisión de conocimientos con profesores físicamente presentes. Esto origina un choque inicial que puede superarse muy rápidamente con explicaciones que les permitan comprender cómo funciona esta nueva lógica de enseñanza-aprendizaje. A la mayoría le toma poco tiempo aprender la dinámica, pero a algunos les sigue haciendo falta la presencia del profesor (Garrison y Kanuka, 2004).

Los estudiantes que llegan a la Universidad Nacional de Colombia tienen grandes dificultades para actuar como estudiantes autónomos que asumen un compromiso o una responsabilidad importante frente a sus procesos de aprendizaje. Este factor es determinante para el éxito de este tipo de cursos. Sin embargo, en ellos se requiere un profesor y un estudiante que entiendan que el proceso de enseñanza-aprendizaje es un proceso que implica un trabajo cooperativo; tanto estudiantes como profesores deben hacer su mejor esfuerzo para aprender y enseñar, de lo contrario, existirán intereses encontrados y opuestos.

Asimismo, se observó que, para lograr el desempeño deseado en cuanto a la categoría de proceso, no es suficiente con un curso que termina siendo un esfuerzo aislado que no se experimente en el contexto de inicio de la vida universitaria, con acompañamiento de otros profesores de las distintas facultades.

Además, aunque los estudiantes mostraron avances en la mayoría del subproceso de escritura, los textos finales muestran aún muchos aspectos por mejorar, sobre todo en lo que tiene que ver con la construcción de argumentos que vayan más allá de opiniones personales poco fundamentadas, pareceres o experiencias subjetivas. Pudimos observar que, mientras mejoraban procesos propios de la planeación, transcripción y edición de los textos, se manifestaba la fragilidad de los procesos de pensamiento lógico, relacionados con la argumentación académica (Padilla, 2012). Lo anterior puede llevarnos a pensar que dedicar esfuerzos a lograr el desarrollo de la habilidad argumentativa puede jalonar los procesos de pensamiento necesarios para que los estudiantes participen de la vida universitaria en las distintas disciplinas del conocimiento.

\section{Conclusiones}

En el contexto de las investigaciones sobre escritura académica en los estudios superiores, y los cursos o programas que busquen su desarrollo, este trabajo ha querido aportar algunas consideraciones para la discusión acerca de las alternativas tecnológicas para ocu- 
parse de la escritura en las aulas universitarias. Podemos concluir que, por un lado, existe una relación entre la calidad de los escritos académicos estudiantiles y las condiciones en las que se desarrolló el curso; y por otro, entre las características de esa aula remota (presagio) y la incidencia de actividades propias del proceso de escritura, planeación, transcripción, edición, revisión apoyada en unas herramientas tecnológicas adecuadas y una didáctica enfocada en el proceso.

\section{Referencias}

Álvarez, G. (2012). Las nuevas tecnologías en el contexto universitario: sobre el uso de blogs para desarrollar las habilidades de lectoescritura de los estudiantes. RUSC: Universities and Knowledge Society Journal, 9(2), 3-17.

Atwell, N. (2007). The reading zone. New York: Scholastic.

Barnett, M. A. (1989). Writing as a process. The French Review, 63(1), 31-44.

Bazerman, C., Krut, R., Lunsford, K., McLeod, S., Null, S., Rogers, P. y Stansell, A. (eds.) (2009). Traditions of writing research. Nueva York: Routledge.

Bolshakov, I. A. y Gelbukh, A. (2004). Computational linguistics models, resources, applications. México: Centro de Investigación en Computación/Instituto Politécnico Nacional.

Bourdieu, P. (2005). Habitus. Habitus: A sense of place, 2, 43-49.

Bronfenbrenner, U. (1987). La ecología del desarrollo humano: experimentos en entornos naturales y diseñados. Barcelona: Paidós.

Camps, A. y Ribas, T. (dirs.) (2000). La evaluación del aprendizaje de la composición escrita en situación escolar: memoria de investigación. Madrid: Ministerio de Educación, Cultura y Deporte.

Carlino, P. (2003). Alfabetización académica: un cambio necesario, algunas alternativas posibles. Educere, 6(20), 409-420.

Castañeda, L., \& Adell, J. (2013). Entornos Personales de Aprendizaje: claves para el ecosistema educativo en red. Alcoy: Marfil. ISO 690

Castelló, M. (2007). El proceso de composición de textos académicos. En M. Castelló (coord.), Escribir y comunicarse en contextos científicos y académicos: conocimientos y estrategias (pp. 47-82). Barcelona: Graó.

Dalton, R. y Dalton, M. (1990). The student's guide to good writing. Nueva York: The College Board Publications.

Dunkin, M. J. y Biddle, B. J. (1974). The study of teaching. Oxford: Holt, Rinehart \& Winston.

Escamilla, J. (2007). Hacia un aprendizaje flexible sin fronteras y limitaciones tradicionales. En A. Lozano Rodríguez y V. Burgos Aguilar (coords.), Tecnología educativa en un modelo de educación a distancia centrado en la persona (pp. 21-52). México: Limusa.

Flórez, R. y Cuervo, C. (2005). El regalo de la escritura: cómo aprender a escribir. Bogotá: Universidad Nacional de Colombia. 
Flórez-Romero, R., Arias-Velandia, N. y Cuervo-Echeverri, C. L. (2006). La experiencia del alfabetismo emergente y otras maneras de ver la lectura y la escritura en la educación inicial. En Memorias VI Congreso Internacional de Investigación en Educación y Pedagogía (pp. 256-262). Bogotá: Instituto para la Investigación Educativa y el Desarrollo Pedagógico.

Garrison, D. R. y Kanuka, H. (2004). Blended learning: Uncovering its transformative potential in higher education. The Internet and Higher Education, 7(2), 95-105.

González, J. E. y Muñetón, M. A. (2002). Dificultades de aprendizaje de la escritura: aplicaciones de la psicolingüística y de las nuevas tecnologías. Madrid: Trotta.

Gutiérrez Rodríguez, M. J. y Flórez Romero, R. (2012). Enseñar a escribir en la universidad: saberes y prácticas de docentes y estudiantes universitarios. Magis: Revista Internacional de Investigación en Educación, 4(7), 137-168.

Hacker, D. (1998). The bedford handbook (5. ${ }^{\mathrm{a}}$ ed.). Boston: Bedford Books.

Henao, A. (2016). Influencia de la tecnología en las competencias analíticas, reflexivas, argumentativas y el desarrollo del pensamiento crítico en el ambiente de aprendizaje colaborativo del curso de español de la universidad de los Andes: estudio de caso. Bogotá, Colombia.

Kelly, D. (2002). Un modelo de competencia traductora: bases para el diseño curricular. Puentes: Hacia nuevas investigaciones en la mediación intercultural, 1, 9-20.

Kemmis, S., Wilkinson, J., Edwards-Groves, C., Hardy, I., Grootenboer, P. y Bristol, L. (2013). Changing practices, changing education. Springer.

Matzat, U. (2004). Cooperation and community on the Internet: Past issues and present perspectives for theoretical-empirical internet research. Analyse \& kritik, 26(1), 63-90.

Maxwell, J. A. (2012). A realist approach for qualitative research. Los Ángeles: Sage.

Milian, M. (1996). Incidencia del contexto en el proceso de producción de textos escritos. Cultura y Educación, 8(2), 67-78.

Moya, C. y Fajardo, L. (2006). Taller de gramática y redacción de textos argumentativos. Bogotá: Universidad Nacional de Colombia.

Oakman, R. L. (1984). Computer methods for literary research. Athens, Georgia: University of Georgia.

Oakman, R. L. (1994). The evolution of intelligent writing assistants: trends and future prospects. En Tools with Artificial Intelligence, 1994. Proceedings., Sixth International Conference on (pp. 233-234). New Orleans: IEEE.

Padilla, C. (2012). Escritura y argumentación académica: trayectorias estudiantiles, factores docentes y contextuales. Magis: Revista Internacional de Investigación en Educación, 5(10), 31-57.

Rué, J. (2009). El aprendizaje autónomo en educación superior. Madrid: Narcea.

Sánchez, C. H., Serrano, G. y Peña, J. I. (2009). Argumentación y lógica: herramientas para un análisis crítico de argumentos. Bogotá: Universidad Nacional de Colombia. 
Sharples, M. (1994). Computer support for the rhythms of writing. Computers and Composition, 11(3), 217-226.

Varón Rondón, G. L. y Moreno Angarita, M. (2009). Escritura académica y ambientes virtuales de aprendizaje en la educación superior. Bogotá: Universidad Nacional de Colombia.

Vicente, J. L. de (2005). Inteligencia colectiva en la web 2.0. Elástico.net, 22, 81-82.

Waldrep, T., Oakman, R., \& Baker, C. (1990). Edit!. McGraw-Hill.

\title{
Anexos
}

\section{Anexo 1. Examen inicial (prueba formativa)}

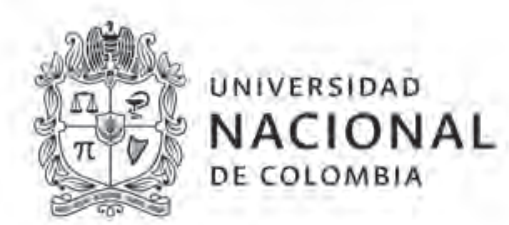

Departamento de la Comunicación Humana

Curso: Comunicación oral y escrita I/Lectoescritura

Prueba formativa

\begin{abstract}
Fecha Sede:

Nombre: Código:

Carrera:

El curso Comunicación Oral y Escrita/Lectoescritura hace parte del proyecto Programa de Mejoramiento de Competencias Comunicativas de los Estudiantes en la Universidad, el cual pretende optimizar los procesos de oralidad, lectura y escritura para el éxito personal, académico y social. El siguiente ejercicio tiene el objetivo de que reflexione sobre sus actitudes, procesos y productos cuando se enfrenta a estas tareas. Procure ser lo más sincero posible. Este ejercicio no es calificable.
\end{abstract}




\section{Qué entiende de los siguientes conceptos:}

- Comunicación:

- Lenguaje:

- Habla:

- Lengua:

- Lectura:

- Código: 
Aportes a la investigación sobre Educación superior virtual desde América Latina

- Coherencia:

- Cohesión:

- Signo:

- Significado:

- Proposición:

- Preposición: 
- Metáfora:

\section{Escriba correctamente las siguientes palabras:}

- Linguiztica:

- Cognisión:

- Entonses:

- Havía:

- Provar:

- Certificado:
- Fabor:

- Planeasión:

- Intervensión:

- Devido:

- Versión:

- Redacion:
- Grasias:

- Herror:

- Univercidad:

- Refleccion:

- Educasion

3. Explique la diferencia que se da entre las siguientes oraciones e identifique el elemento que es desplazado (Moya y Fajardo, 2006):

a- Recibí cierta información frente a Recibí información cierta

b. Me hospedé en un gran hotel frente a Me hospedé en un hotel grande 
c. Tengo un amigo bueno frente a Tengo un buen amigo

4. Reescriba el siguiente párrafo para que tenga coherencia y cohesión, escribiéndolo con el orden sintáctico más frecuente en la lengua (Moya y Fajardo, 2006).

La universidad debe en la investigación hacer énfasis ya que el estudiante debe recibir, desde los semestres primeros, una orientación que lo capacite para manejar el científico método; aunque la realidad es bien diferente, puesto que el estudiante llega a realizar su grado de trabajo y aún no sabe cómo investigar, debido a que predominantemente memorística su educación ha sido y la creatividad no se le ha incentivado; así que el egresado profesional no podrá contribuir la ciencia y de la técnica al desarrollo de. Por lo tanto, tiene que cambiar la universidad su sistema educativo y formar capaces profesionales e investigadores de hacer aportes útiles al país. 
Comunicación, redes, aprendizaje y desarrollo institucional y social

\section{Coloque el acento ortográfico a las palabras que deben llevarlo (Moya y Fajardo, 2006):}

a. ¿Cuándo se hirió? Cuando jugaba. Pero no dice cuando fue ni dónde.

b. De su punto de vista sobre este asunto. Yo no sé nada de ese tema, más bien le puedo dar mis opiniones sobre este que estoy estudiando.

c. Se amable con esa joven. Yo no sé por qué tú me pides eso ¿Sera porque la aprecias mucho? A mi ella no me interesa en cambio aquella si me agrada. Aun no entiendo por qué.

\section{Relacione el texto con los elementos cohesivos que aparecen al final.}

Algunos años después, la existencia de la soñolienta Aracataca se vio sacudida por "la fiebre del banano", llegó desde la cuenca del río Magdalena, lugar en que desde el

comienzo del siglo gobierna United Fruit Company. Millares de buscadores de fortuna colmaron la ciudad.

Relegados al segundo plano, los habitantes oriundos mantenían apartados de los forasteros, marcando__- con el despreciativo apodo de "hojarasca". Por eso, cuando uno de los forasteros, _-_- telegrafista Gabriel García, se enamoró de la hija del coronel Márquez y correspondió, los padres hicieron todo posible por evitar matrimonio ((Moya

y Fajardo, 2006).

Elementos cohesivos: su, ésta, lo, aquí, los, se, el, le, la, ella.

\section{Lea el enunciado y marque la respuesta correspondiente a cada pregunta.}

a. "Hubo un tiempo en que la metafísica recibió el honroso título de reina de todas las ciencias y ahora yace desterrada como una miserable". De la anterior afirmación podemos suponer que:

A. La metafísica siempre ha sido considerada como la reina de todas las ciencias.

B. La metafísica en la historia del pensamiento ha alcanzado grandes peldaños.

C. La metafísica fue considerada ciencia primera pero ahora se le desconoce.

D. El pensamiento metafísico se ha convertido en base de las demás ciencias.

b. Escribe Descartes: “Bueno es saber algo de las costumbres de otros pueblos para juzgar las del propio con mayor acierto y no creer que todo lo que sea contrario a nuestros modos sea ridículo y opuesto a la razón, como suelen hacer los que no han visto nada". A partir de lo anterior se deduce que todo juicio acerca de las costumbres de otro pueblo tiene que: 
A. Estar basado en el reconocimiento de la diversidad cultural propia de las sociedades humanas.

B. Tomar como punto de partida la capacidad para adaptarse a otras costumbres diferentes.

C. Juzgar como malo todo lo que se oponga a la moral imperante en comunidades heterogéneas.

D. Ser el resultado de un recorrido existencial capaz de establecer los criterios de la moral.

8. ¿Qué entiende por lógica?

9. ¿Conoce algunos tipos de argumentos? Enúncielos y dé un ejemplo.

10. ¿Qué es el razonamiento?

11. ¿Conoce el significado de "falacia" en la argumentación? Si no, en su opinión, ¿qué considera que puede significar? Dé un ejemplo.

12. ¿Qué tipos de texto lee frecuentemente? 
13. ¿Qué estrategias utiliza cuando lee para aprender?

14. Cuando usted lee textos académicos, ¿qué estrategias utiliza para comprender?

15. Cuando usted escribe, ¿qué pasos sigue para redactar un buen texto?

16. ¿Qué tipos de texto prefiere escribir?
A. Narrativos
B. Expositivos
C. Argumentativos
D. Descriptivos
E. Cualquier tipo de texto

\section{Defina:}

Texto narrativo: 
Aportes a la investigación sobre Educación superior virtual desde América Latina

Texto expositivo:

Texto argumentativo:

Texto descriptivo: 


\section{Anexo 2. Rejillas de revisión de textos argumentativos}

\begin{tabular}{|c|c|c|}
\hline Lista de chequeo de los siete aspectos más importantes & Sí & No \\
\hline \multicolumn{3}{|l|}{ 1. Lógica } \\
\hline \multicolumn{3}{|l|}{ ¿Existe una tesis o enunciado central? } \\
\hline \multicolumn{3}{|l|}{ ¿Tienen secuencia lógica los párrafos? } \\
\hline \multicolumn{3}{|l|}{ ¿Tienen secuencia lógica las oraciones? } \\
\hline \multicolumn{3}{|l|}{ ¿Existen hechos, datos específicos, detalles, razones que apoyen la tesis? } \\
\hline \multicolumn{3}{|l|}{ 2. Claridad } \\
\hline \multicolumn{3}{|l|}{ ¿Existen lugares en el escrito que no tienen sentido? } \\
\hline \multicolumn{3}{|l|}{ ¿Existen oraciones que no son claras? } \\
\hline \multicolumn{3}{|l|}{ ¿Se enuncian las ideas de manera simple? } \\
\hline \multicolumn{3}{|l|}{ ¿Se define con claridad la terminología? } \\
\hline \multicolumn{3}{|l|}{ 3. Léxico } \\
\hline \multicolumn{3}{|l|}{ ¿Predominan los verbos activos? } \\
\hline \multicolumn{3}{|l|}{ ¿Predominan los verbos pasivos? } \\
\hline \multicolumn{3}{|l|}{$\begin{array}{l}\text { ¿Hay lugares donde una palabra podría reemplazar varias? } \\
\text { ¿Hay palabras mal usadas? }\end{array}$} \\
\hline \multicolumn{3}{|l|}{ ¿Se limitan las palabras a sonar bien en vez de significar algo? } \\
\hline ¿Se han usado sinónimos de manera apropiada en vez de simplemente repetir palabras? & & \\
\hline \multicolumn{3}{|l|}{ 4. Audiencia } \\
\hline \multicolumn{3}{|l|}{ ¿Se identifica la audiencia? } \\
\hline \multicolumn{3}{|l|}{ ¿Es consistente la voz del escrito? } \\
\hline \multicolumn{3}{|l|}{ ¿Es coherente el léxico con la audiencia? } \\
\hline \multicolumn{3}{|l|}{ 5. Energía } \\
\hline \multicolumn{3}{|l|}{ ¿Tiene energía el tema? } \\
\hline \multicolumn{3}{|l|}{ ¿Tiene energía el escrito? } \\
\hline \multicolumn{3}{|l|}{ ¿Tiene energía el léxico? } \\
\hline \multicolumn{3}{|l|}{ 6. Elaboración } \\
\hline \multicolumn{3}{|l|}{ ¿Se exploró el tema desde todos los ángulos? } \\
\hline \multicolumn{3}{|l|}{ ¿La discusión está detallada y desarrollada? } \\
\hline \multicolumn{3}{|l|}{ 7. Mecánica } \\
\hline \multicolumn{3}{|l|}{ ¿Hay errores de ortografía? } \\
\hline \multicolumn{3}{|l|}{ ¿Hay errores de gramática? } \\
\hline ¿Es adecuada la puntuación? & & \\
\hline
\end{tabular}

Fuente: Hacker (1998, pp. 46-47) y Dalton y Dalton (1990). 


\section{Pauta de revisión de un texto argumentativo (Milian, 1994, citado en Camps y Ribas, 2000)}

\begin{tabular}{|c|c|c|}
\hline 1. Elementos de argumentación & Sî & No \\
\hline 1.1¿Queda claro el receptor del texto? & & \\
\hline 1.2 ¿Queda claro a quién queremos convencer? & & \\
\hline 1.3 ¿Queda claro quién escribe el texto? & & \\
\hline 1.4 ¿Definimos claramente nuestra tesis? & & \\
\hline 1.5 ¿Damos argumentos para justificarla? & & \\
\hline 1.6 ¿Aceptamos alguna opinión de los oponentes? & & \\
\hline 2. Organización del texto. ¿Dónde aparece la tesis? & & \\
\hline 2.1 Al inicio & & \\
\hline 2.2 Al final & & \\
\hline 2.3 Aparece más de una vez & & \\
\hline 2.4 No aparece & & \\
\hline ¿Cuántos argumentos hemos dado para defender nuestra opinión? & & \\
\hline 2.5 Todos los de la lista de planificación & & \\
\hline 2.6 Unos cuantos & & \\
\hline 2.7 Un único argumento & & \\
\hline 2.8 Ninguno & & \\
\hline Tipos de argumentos & & \\
\hline $\begin{array}{l}2.9 \text { Hay argumentos basados en opiniones de algún científico o de personalidades } \\
\text { reconocidas en la materia }\end{array}$ & & \\
\hline 2.10 Hay argumentos justificados con datos objetivos o ejemplos & & \\
\hline 2.11 Los argumentos se justifican en nuestra experiencia personal & & \\
\hline 2.12 Los argumentos son opiniones personales no justificadas & & \\
\hline ¿Cómo se presentan los argumentos? & & \\
\hline 2.13 Se presentan en un solo párrafo, uno detrás de otro & & \\
\hline 2.14 Hay argumentos en cada párrafo, con ejemplos y explicaciones & & \\
\hline 2.15 Hay elementos que marcan el orden de los argumentos & & \\
\hline 2.16 Se contrastan los argumentos con los contraargumentos en el mismo párrafo & & \\
\hline 2.17 Los argumentos y los contraargumentos se presentan en párrafos distintos & & \\
\hline 2.1 8 Se usan elementos lingüísticos para marcar la aceptación de los contraargumentos & & \\
\hline
\end{tabular}


Comunicación, redes, aprendizaje y desarrollo institucional y social

Anexo 3. Formato de evaluación final

\title{
1 1] Universidad de
}

\author{
Departamento de la Comunicación Humana \\ Curso: Comunicación Oral y Escrital/Lectoescritura
}

Evaluación final del curso (adaptado del Centro de Español de la Universidad de los Andes,

httpprogramadeescritura.uniandes.edu.co)

Este ejercicio de escritura contiene tres documentos:

- Una noticia

- Una columna de opinión escrita por el padre Alfonso Llano

- Una columna de opinión escrita por Yolanda Puyana Villamizar

La entrevista y la columna presentan la posición de dos personajes públicos frente a la adopción de niños por parejas conformadas por personas del mismo sexo. Alfonso Llano aborda el tema usando como criterio la idoneidad moral, mientras que Yolanda Puyana lo hace a partir de las capacidades que tienen las parejas del mismo sexo para conformar una familia.

Usted debe escribir un texto en el que argumente cuál es su posición frente a la aprobación de la adopción de niños por parejas conformadas por personas del mismo sexo y explicar cómo se relaciona esta posición -la suya - con las ideas de los dos personajes.

\section{Recomendaciones de escritura}

1. Lea los tres textos.

2. Realice en una de las hojas en blanco una planeación del texto argumentativo que es- 
tructurará presentando: tema, tesis, audiencia, propósito, y exponiendo las ideas o argumentos que expondrá.

3. En las demás hojas en blanco, realice su texto argumentativo, teniendo en cuenta la planeación que realizó y ponga en práctica todos los conocimientos aprendidos en clase en los temas de lógica y argumentación y escritura.

4. Tenga presente que debe ser un ejercicio totalmente individual.

5. Su experiencia y conocimiento sobre el tema son importantes. No olvide sustentar todo lo que escriba acerca del tema teniendo en cuenta la información proporcionada por las lecturas.

6. Haga un uso responsable de las fuentes. Si usa palabras textuales de los textos asignados use comillas e indique la fuente. En el transcurso del texto, realice citación y presente al final de este las referencias bibliográficas conforme a las normas APA.

\section{Noticia}

Corte constitucional analiza demanda contra el código de la infancia CMI | Actualizado el lunes, 03 de septiembre de 2012 12:07

Por medio de una demanda piden declarar inconstitucional un artículo de la Ley de Infancia y Adolescencia.

La Corte Constitucional entró con ponencia negativa en la discusión de otra demanda con la que se busca abrir un camino legal para la adopción gay. Varios académicos interpusieron una acción legal con la cual piden decretar inconstitucional un artículo de la Ley de Infancia y Adolescencia, que se fundamenta en la idoneidad moral de quienes buscan ser padres por medio de la adopción. En el documento se pide que se impulse al Congreso para que busque llenar los vacíos jurídicos respecto al matrimonio. 


\section{Columna del padre Alfonso Llano 'Idoneidad moral'}

EL Tiempo| 9 de septiembre de 2012

Estoy de acuerdo con el parecer de la Corte Constitucional según el cual las parejas homosexuales carecen de la idoneidad moral requerida para justificar la adopción de menores. Quiero poner de relieve varios hechos importantes:

1. ¿Quién lo dice? No es el Papa, no algún moralista retrógrado, ni un censor, pasado de moda, de los homosexuales. No. Nada de eso. Lo dice nadie menos que la Corte Constitucional que es ajena a todo prejuicio religioso o moralizador. La Corte Constitucional, al emitir este parecer, no mira al bien de los adoptantes sino, como debe ser, al bien de los adoptados. Se trata de seres humanos, dignos de toda consideración y aprecio, de seres humanos en formación, que reclaman el ambiente más idóneo para la formación de su conciencia.

2. ¿A quién se refiere la Corte? A las parejas homosexuales: dos hombres o dos mujeres que conviven bajo un mismo techo y desean la compañía de uno o dos niños para llenar su vacío y su carencia de afecto. ¿Para bien de ellos o de los niños? Seguramente, de ellos, que añoran la familia, el hogar. Algo les falta, ¿verdad?

3. ¿Cuál es la causa? La falta de idoneidad moral. Por idoneidad se entiende la aptitud o adecuación de algo para algo. Con todo el respeto del caso, lo que la Corte Constitucional echa de menos, al rechazar la eliminación del requisito de la "idoneidad moral" en la ley es la idoneidad moral de la pareja homosexual para formar en valores la conciencia de los niños. Formar la conciencia de un niño es la tarea más delicada, responsable y difícil que Dios ha confiado a las parejas heterosexuales, que constituyen, por la complementariedad de sus atributos propios, el ambiente ideal para dicha formación de la conciencia. Sabemos que la conciencia moral de los niños se forma precisamente a esa edad, y que un factor decisivo, quizás no el único, pero sí uno necesario y esencial, es la presencia de la madre. Nadie como ella posee la idoneidad para formar la conciencia de los niños. Para ello, contribuyen de manera eficaz y directa el ambiente del hogar, los valores morales que se cultivan en él, para que el niño los vaya asimilando gradualmente.

La Corte Constitucional supone que una pareja homosexual no aporta el ambiente idóneo para formar la conciencia de los niños. Alli falta el hogar, el calor de la familia, la complementariedad de los dos sexos, la delicadeza de la madre -en pareja masculina-, el cariño, el 
respeto, la altura de miras, el ejemplo de una vida que no tiene nada que ocultar, y sí tiene mucho para dar. Estas cualidades suelen estar ausentes en parejas homosexuales.

La idoneidad moral viene formada por lo normal, lo habitual, nunca por lo excepcional. Así que los casos excepcionales no permiten aducir lo contrario. Que, excepcionalmente, algunas parejas homosexuales cuenten con dicha idoneidad para la educación de menores o que, excepcionalmente, algunas parejas heterosexuales carezcan de dicha idoneidad, no es un argumento para aducir favor de la adopción. La excepción confirma la regla pero jamás la crea.

No estoy afirmando que, por este rechazo, la Corte Constitucional pretende introducir una discriminación en contra de las parejas homosexuales. Es mucho, quizás demasiado, lo que han conseguido. Lo que quieren es pasar por normales, con iguales derechos que los matrimonios heterosexuales. Veo bien el ayudar a dichas parejas a asumir un hecho poco agradable, que merece todo respeto: la tendencia homosexual, que por mucho que se respete, nunca va a ser algo deseable y digno, algo normal. En mí ya larga vida, nunca he oído a unos padres de familia proclamar a los cuatro vientos, ufanos y contentos: "Tenemos un hijo homosexual. ¡Qué suerte! ¡Qué dicha!”. Está bien sacarlos del clóset, pero jamás sentarlos en la vitrina.

Invito a que seamos sensatos: la adopción de menores por parte de parejas homosexuales no es asunto religioso, es cuestión de sensatez, de responsabilidad, de amor a los niños y al futuro de la sociedad.

\section{Columna de Yolanda Puyana Villamizar Adopción y parejas del mismo sexo: ¿por qué no?}

Domingo, 06 de Mayo de 2012 22:57

Ante los millones de niños y niñas abandonados o mal atendidos en Colombia, la adopción deseada es una bendición, tanto para la pareja como para el infante. Y sin embargo los prejuicios homofóbicos prefieren negar ese derecho. El debate se reabre.

Durante las últimas semanas han vuelto a agitarse las banderas contra la formación de familias de personas del mismo sexo. Estas uniones han sido calificadas como "antinaturales" y “dañinas para el bienestar de la sociedad” por la iglesia Católica, por el inefable Procurador -típico patriarca tradicionalista- y por otros dirigentes. Ellos reciben el respaldo de diversos sectores que se resisten a ver cómo cambia la sociedad y seguirán argumentando sobre la necesidad de recuperar la familia nuclear en Colombia. 
Los grupos familiares colombianos siguen cambiando a pesar de todo y los siguientes fenómenos son indicativos de la tendencia hacia una mayor secularización de la sociedad. Cada vez es más baja la tasa de fecundidad en las grandes ciudades, el uso de anticonceptivos se ha generalizado, la capacidad de las madres o de los padres para decidir sobre cuándo y en qué circunstancias desean un hijo o una hija ha aumentado, los hogares monoparentales en cabeza de mujeres han aumentado.

\section{El derecho también evoluciona}

La Constitución de 1991 promulgó una concepción sobre familia que sin duda excluye el derecho de las parejas homosexuales a conformarlas. Pero en ese momento también se dio un cambio fundamental: la separación entre las iglesias y el Estado y, por ende, un marco constitucional para que la ética personal rija la vida cotidiana de los grupos familiares. Durante veintiún años de vigencia de la Constitución, la Corte ha ido construyendo una interpretación flexible frente a los cambios de los grupos familiares y ha ido fijando una jurisprudencia clara ante las demandas de la población LGTBI. Paulatinamente ha reconocido que una pareja del mismo sexo - que cohabite en forma estable y comparta un proyecto de vidapuede constituirse ante la ley en una familia. Esto significa otorgarles el mismo respeto y la misma dignidad de las familias conformadas por parejas heterosexuales.

En este marco, la Corte delegó al Congreso la legislación al respecto, suponiendo que si en dos años este no se pronuncia, tales familias tendrían los mismos deberes y derechos que las demás. Un aspecto crucial de la legislación es regular el derecho de estas familias a adoptar. Hasta la fecha la Corte no se ha pronunciado, y esta misma semana se anunció el aplazamiento de la esperada sentencia sobre la acción de tutela que interpusieron dos colombianas casadas bajo leyes alemanas contra el Defensor Segundo de Familia de Rionegro (Antioquia) por negarles la posibilidad de adoptar.

En mi opinión, los legisladores han "naturalizado" la paternidad y la maternidad, me imagino que esto se explica porque aún prevalece la creencia de que los homosexuales y las lesbianas son enfermos y que van a trasmitir sus trastornos a la descendencia. Varias reflexiones me llevan a asumir una posición favorable al derecho que tiene la población LGTBI en Colombia a adoptar. En primer lugar, estoy a favor de la adopción porque entiendo que la paternidad y la maternidad son construcciones sociales, cambiantes e históricas. La segunda razón es que las investigaciones científicas indican que tanto parejas del mismo sexo, como heterosexuales, son aptas para adoptar. Finalmente, estoy a favor porque considero que la situación de la niñez colombiana es tan difícil per se, que su cuidado y apoyo a partir del deseo, debería ser responsabilidad de todos y todas. 


\section{La familia, construcción social}

Desde la Colonia, en Colombia tenemos documentación suficiente para mostrar cómo los padres han abandonado con frecuencia a su prole y ha sido común que las madres deban hacerse cargo de sus hijas e hijas. Adicionalmente, según la encuesta de Profamilia de 2010, los hogares con jefes mujeres ascendieron al 34 por ciento en el país. En varias regiones -y en particular en la Pacífica y Caribe- ha sido común que las abuelas sean las madres de crianza y constituyan el centro del hogar, mientras que las jóvenes realizan actividades generadoras de ingreso. Según esto, las funciones paternas y maternas no han estado exclusivamente a cargo de quienes biológicamente han procreado, sino que cumplen un papel en la socialización. También lo hacen las redes parentales y sociales que ejercen estas tareas, incluso las interacciones afectivas y amorosas. No obstante, la idealización de la familia nuclear insiste en reconocer solamente ejercicio de la paternidad y de la maternidad en los lazos de consanguinidad exclusivamente.

Por otra parte, se han adelantado investigaciones sobre la idea de que las parejas del mismo sexo podrían tener características desfavorables para la adopción. Estas investigaciones han coincidido sistemáticamente en conclusiones similares a las de la Asociación Psicológica Canadiense, que cito a continuación: “Las creencias de que los adultos gays y lesbianas no son buenos padres, o que el desarrollo psicológico de los niños de padres gays o lesbianas está comprometido, no tiene bases en la ciencia. Nuestra posición se basa en una revisión que representa aproximadamente 50 estudios empíricos". El juicio se sustenta en que tanto parejas del mismo sexo como heterosexuales, mostraron capacidades similares para desarrollar la crianza y el cuidado y cumplieron con una cualidad central para la adopción de niños o niñas: el deseo de ser padres y madres.

En el caso de Colombia, los estudios apenas se inician. Tras revisar el estado del arte encontramos, por ejemplo, una investigación realizada en España señala que los problemas de la crianza no se deben a la conformación sino a los conflictos dentro de la familia. Según el texto: “La orientación sexual de los progenitores, en sí mismos, no parecen ser una variable relevante a la hora de determinar el modo en que se construye el desarrollo y ajuste psicológico de hijos e hijas". Lo que, en cambio, sí hace daño es la violencia contra las familias homoparentales, fruto de nuestra intolerancia e incapacidad de soportar la diversidad.

\section{Toda adopción deseada es una lotería}

En la última encuesta de Profamilia (2010) aparece un dato acerca de la desprotección de la infancia en Colombia: el 4 \% de los niños son huérfanos y el 7 \% viven con cuidadores que no son sus padres o madres biológicos. Este último porcentaje crece en lugares dominados 
Comunicación, redes, aprendizaje y desarrollo institucional y social

por las culturas Pacífica o Caribe, y que además se encuentran en regiones afectadas por el conflicto armado: 15 por ciento en el Chocó, 14 por ciento aproximadamente en Córdoba y Sucre. Al mismo tiempo, numerosos estudios han mostrado cómo la pobreza se concentra en niños y niñas, en particular, si estos han sido afectados por el conflicto armado.

Los estudios para evaluar la protección de menores por parte del ICBF indican que la mejor alternativa es sencillamente tener un hogar: padres y madres de crianza. El matoneo es intenso entre quienes cohabitan en instituciones y con frecuencia esos niños crecen hostiles y resentidos contra una sociedad que los abandonó. Muchos de los niños que habitan en estos centros de protección se angustian, se sienten frustrados y sin salida cuando no encuentran quien los adopte y esperan ansiosamente que ese sueño se realice. Mi experiencia como terapeuta en centros de protección de la Secretaria de Integración Social en Bogotá con niñas y niños declarados en abandono por un juez, también me ha llevado a pensar que la mejor opción es la adopción. Obviamente, debe haber mecanismos legales y éticos bien definidos, a partir de una disposición positiva de padres y madres para cumplir plenamente con esta función y después de haber recibido una orientación adecuada.

Finalmente, me pregunto: ¿por qué prejuicios sin fundamento científico niegan el derecho a las parejas del mismo sexo a gozar de la paternidad y de la maternidad y a unos niños o niñas el derecho a desarrollarse en condiciones más favorables que las ofrecidas por las instituciones oficiales? 